\title{
Contribuição para a avaliação de ciclo de vida na quantificação de impactos ambientais de sistemas construtivos
}

\author{
Contribution of life cycle assessment to the \\ quantification of the environmental impacts of \\ construction systems
}

\section{Larissa Mendes Medeiros \\ Luciane Cleonice Durante Ivan Júlio Apolonio Callejas}

\section{Resumo}

$\mathbf{E}$

ste estudo consiste em uma avaliação do ciclo de vida (ACV) aplicada a uma edificação de ensino localizada na região Centro-Oeste do Brasil. O objetivo foi identificar a contribuição dos sistemas construtivos de fundação e superestrutura, ambos em concreto armado, vedações compostas por tijolos cerâmicos e argamassas, cobertura com telhas termoacústicas, esquadrias em alumínio e revestimentos cerâmicos nas categorias de impacto ambiental definidas na metodologia. Considerou-se a abordagem de berço ao portão para uma unidade funcional de $1,0 \mathrm{~m}^{2}$ de área construída. O inventário do ciclo de vida (ICV) foi elaborado a partir da base de dados Ecoinvent 2.0, adotando-se o World ReCiPe midpoint H como método de avaliação do impacto do ciclo de vida (AICV). Utilizou-se o software SimaPro 8.0 para modelagem. Constatou-se que os sistemas de superestrutura, cobertura e vedações foram os mais contributivos, o que reforça a necessidade de busca de alternativas inovadoras para minimizar os impactos ambientais dos sistemas tradicionalmente praticados. Contribui-se dessa forma para o desenvolvimento da ACV no Brasil ao se discutir os gargalos e dificuldades encontrados para sua aplicação.

Demonstram-se ainda as adaptações necessárias nos inventários dos processos europeus de fabricação para maior adequabilidade à realidade brasileira, visto que os nacionais ainda são incipientes.

Palavras-chaves: Impactos ambientais. Sistemas construtivos. Análise de sensibilidade.

Larissa Mendes Medeiros Instituto Federal de Mato Grosso Várzea Grande - MT - Brasil

Luciane Cleonice Durante Universidade Federal de Mato Grosso Cuiabá - MT - Brasil

Ivan J úlio Apolonio Callejas Universidade Federal de Mato Grosso Cuiabá - MT - Brasil

Recebido em 12/09/16 Aceito em 06/12/17

\begin{abstract}
This study consists of a Life Cycle Assessment (LCA) applied to a school building located in the Midwestern region of Brazil. The objective was to identify the contribution of the foundation and superstructure systems, both made of reinforced concrete; mortar coated masonry walls; a roof covered with thermo-acoustic tiles; aluminum window frames; and ceramic floors to the environmental impact categories defined in the methodology. The study used the cradle-to-gate approach for a functional unit with 1.0sqm of built area. The Life Cycle Inventory (LCI) was calculated using the Ecoinvent 2.0 database, considering World ReCiPe Midpoint $H$ for the Life Cycle Impact Assessment (LCIA) method. The SimaPro 8.0 software was used for modeling. The conclusion was that the superstructure, roof and masonry walls were the systems that had the greatest impact, which indicates the need to find innovative alternatives to minimize the environmental impacts of the systems usually employed. Hence, this paper contributes to the development of LCA in Brazil, as it discusses the bottlenecks and difficulties observed in its application. This study also demonstrates the need to adapt the European manufacturing processes inventories to the Brazilian reality, since national inventories are still incipient.

Keywords: Environmental impacts. Constructive systems. Sensitivity analysis.
\end{abstract}

MEDEIROS, L. M.; DURANTE, L. C.; CALLEJ AS, I, J . A. Contribuição para a avaliação de ciclo de vida na quantificação 365 de impactos ambientais de sistemas construtivos. Ambiente Construído, Porto Alegre, v. 18, n. 2, p. 365-385, abr./jun. 2018. 


\section{Introdução}

As discussões acerca dos impactos ambientais causados pelas atividades antrópicas, tais como escassez de matéria-prima, acumulação de resíduos, destruição da camada de ozônio, aquecimento global, dentre outros, são temas-alvo de preocupação da sociedade.

Nesse contexto, o setor da construção civil desempenha papel significativo, visto que consome entre $14 \%$ e $50 \%$ de toda a matéria-prima extraída da natureza, $16 \%$ de recursos hídricos e $40 \%$ de toda fonte de energia (TAVARES, 2006). Além disso, gera de $40 \%$ a $70 \%$ dos resíduos sólidos e, ainda, é responsável por $10 \%$ das emissões de gases de efeito estufa na atmosfera. Esse cenário demonstra que o setor tem um grande potencial para buscar soluções sustentáveis que minimizem os impactos gerados por sua atividade.

A ACV é uma técnica para avaliar os potenciais impactos ambientais ao longo de todo o ciclo de vida de um produto, ou seja, do berço ao túmulo, de forma quantitativa (ABNT, 2009a). Para Bilec et al. (2010), a ACV é uma ferramenta sistemática de gestão ambiental que analisa e avalia de forma holística os impactos ambientais de um produto ou processo. Sua aplicação na construção civil, segundo Ortiz, Castells e Sonneman (2009), começou a partir de 1990, constituindo-se, desde então, em uma importante ferramenta de avaliação de desempenho ambiental e avaliação dos impactos potenciais associados a todas as etapas construtivas das obras civis.

O ciclo de vida das edificações é classificado em quatro fases (BRITISH..., 2011): a fase de produção de materiais, que inclui os estágios de extração, transporte e manufatura da matéria-prima; a fase de construção, que considera o transporte até o canteiro, bem como os processos de construção e instalação nele realizados; a fase de uso, que considera todas as reposições de materiais, manutenções, bem como consumo operacional de energia e água; e a fase de fim de vida, na qual são contempladas a demolição, a desconstrução, o transporte, a produção e a disposição de resíduos. Assim, os materiais de construção que após o fim da vida podem ser reciclados ou reincorporados nos processos representam benefícios ambientais.

Soares, Souza e Pereira (2006) ressaltam que a aplicação da ACV em edificações requer algumas alterações em relação à ACV aplicada a produtos industriais, em função, principalmente, da vida útil da edificação que, de acordo com a NBR 15575-1 (ABNT, 2013), é de pelo tempo 50 anos, e também devido ao grande número de materiais e sistemas envolvidos no processo de construção. Acerca da vida útil de uma edificação, Aktas e Bilec (2012) concluíram que nem sempre a adoção de 50 anos é adequada, e demonstraram que o tempo de vida útil médio de uma edificação residencial nos Estados Unidos é de 61 anos, com tendência linearmente crescente.

Cabeza et al. (2014) classificam a literatura da ACV aplicada ao setor de edifícios em: avaliação do ciclo de vida em edifícios industriais e avaliação do ciclo de vida em edificações. Na primeira, enquadram-se estudos referentes à:
(a) construção de produtos;
(b) construção de sistemas/processos de avaliação;

(c) banco de dados e ferramentas relacionadas às construções industriais; e

(d) desenvolvimento de metodologias relacionadas às construções industriais.

Na segunda, reúnem-se os estudos de:

(a) edifícios residenciais;

(b) edifícios não residenciais; e

(c) engenharia da construção civil.

A ACV quando aplicada às edificações pode ser abordada enfocando materiais, sistemas, componentes ou elementos construtivos de forma isolada ou enfocando as edificações como um todo (ASIF; MUNEER; KELLEY, 2007). Ortiz, Castells e Sonnemann (2009) denominam a ACV aplicada aos materiais de construção como building material and component combinations (BMCC), e a ACV aplicada ao processo da construção do edifício de whole process of the construction (WPC).

Considerando o edifício como um todo, Asif, Muneer e Kelley (2007) analisaram uma residência geminada na Escócia considerando seus principais materiais de construção: madeira, alumínio, vidro, concreto e telha cerâmica, determinando a energia embutida e os impactos ambientais associados à categoria de aquecimento global. Os resultados mostraram que o concreto, a madeira e a cerâmica são os materiais mais impactantes, sendo que o concreto, além de ser responsável por $65 \%$ do total da energia embutida da edificação, é responsável por $99 \%$ das emissões da edificação em termos dos gases de efeito estufa $\mathrm{CO}_{2}$, SOx e $\mathrm{NOx}$, devido ao seu processo de produção.

Blengini e Di Carlo (2010) elaboraram uma ACV detalhada de uma edificação sustentável em Morozzo, Itália, e comprovaram que, embora a concepção low-energy tenha reduzido o consumo de energia na fase de uso (a energia para 
aquecimento foi reduzida em 10:1, se comparada a uma edificação padrão), a energia do ciclo de vida foi reduzida apenas em 2,1:1 e a pegada de carbono em 2,2:1. Concluíram que, devido à elevada energia embutida dos materiais construtivos para isolamento nesse tipo de edificação, seus efeitos podem não ser eficazes em uma perspectiva de ciclo de vida. Destacaram que a adoção de materiais com potencial de reciclagem é um instrumento eficaz para diminuir os impactos do ciclo de vida, estimado entre $6 \%$ e $35 \%$, dependendo da categoria de impacto analisada. Aktas e Bilec (2012) também corroboram com os autores acima quando afirmam que a desconsideração dos impactos de renovação dos materiais de acabamento da fase de uso (sendo estes, no caso do estudo, tintas e pisos - carpetes, madeira, linóleo, vinil e cerâmica) influencia nos potenciais impactos, e são especialmente importantes, devido ao crescente número de edifícios de baixo consumo energético nessa fase do ciclo de vida.

A possibilidade de relacionar parâmetros de ACV à certificação energética foi estudada por Lewandowska et al. (2015) na Polônia, e os autores constataram que a redução do consumo de energia para aquecimento, ventilação e água quente na fase de uso das edificações certificadas leva a um acréscimo do uso de materiais de construção para isolamento térmico, como alumínio, aço e vidro que, por sua vez, possuem elevado impacto. Isso leva a uma maior utilização de materiais e energia em outras fases do ciclo de vida, não incluídas na certificação energética. Os resultados obtidos mostraram que as simplificações incluídas na certificação energética levaram a uma queda significativa dos impactos ambientais (em média 77,9\%) em relação ao impacto calculado para o LCA completo. Mudanças nas metodologias que considerem emissões para o ciclo de vida completo podem mudar a ótica das certificações.

Dentre os estudos que analisaram materiais ou sistemas isoladamente, pode-se citar Carlisle e Friedlander (2016), que aplicaram a ACV ao estudo de componentes, comparando quatro tipos de esquadrias: alumínio, madeira, madeira folheada com alumínio e policloreto de polivinila (PVC). Seus resultados evidenciaram que as esquadrias de alumínio são a opção menos impactante em todas as categorias, em grande parte devido aos créditos fornecidos pela reciclagem e às expectativas de longa vida útil com baixa manutenção ao longo da fase de uso, muito embora a energia embutida no seu processo de extração e produção seja muito impactante.

Tait e Cheung (2016), cientes de que o concreto é um dos materiais mais impactantes da construção civil e utilizado no mundo todo, fazem uma abordagem desse material do berço ao portão, incluindo materiais secundários em sua composição, a fim de reduzir as elevadas emissões de $\mathrm{CO}_{2}$ advindas do processo de fabricação do cimento, oferecendo alternativas para seu uso de forma mais sustentável.

No âmbito nacional, citam-se Bueno et al. (2016), que realizaram um estudo comparativo de ACV em cinco sistemas de vedação externa sem função estrutural; Sansão (2011), que investigou a envoltória composta de painéis de blocos de concreto e cerâmico; Campos (2012), que realizou um estudo comparativo entre vedações estruturais em painéis pré-moldados e alvenaria em blocos de concreto; Passuello et al. (2014), que propuseram uma ACV calculando a pegada de carbono para clínqueres alternativos; e Souza et al. (2015), que realizaram um estudo comparativo entre telhas cerâmicas e telhas de concreto.

Ortiz, Castells e Sonnemann (2009) afirmam que existem mais estudos de ACV aplicados a partes específicas, como sistemas e componentes, do que ao edifício como um todo. Nos estudos nacionais também se verifica tal realidade. Isso se deve, em grande parte, à inexistência de um inventário nacional e, também, à complexidade e às incertezas envolvidas nos estudos de ACV aplicados à edificação, sobretudo quando se utilizam bases de dados internacionais.

Este estudo se utiliza da ACV aplicada ao contexto da construção civil em Mato Grosso, estado da região Centro-Oeste do Brasil, onde se percebe que a preocupação com o tema ainda é incipiente. Foram identificados apenas dois exemplos locais de obras que buscaram melhor desempenho ambiental: a Arena Pantanal (PINI, 2013) e o edifício do Serviço Brasileiro de Apoio a Micro e Pequenas Empresas (Sebrae), denominado Centro Sebrae de Sustentabilidade (SERVIÇO..., 2016).

O projeto da Arena Pantanal recebeu diversos prêmios de sustentabilidade, inclusive um internacional, e foi elaborado seguindo os critérios para certificação Leadership in Energy and Environmental Design (LEED). Esse empreendimento foi edificado no mesmo terreno do antigo estádio Governador José Fragelli, que, demolido, teve seus resíduos de concreto reutilizados no subleito de pavimentação, suas cadeiras e cobertura metálica reaproveitadas em outros estádios e o aço das ferragens encaminhado para reciclagem (PINI, 2013). O Centro Sebrae de Sustentabilidade, por sua vez, tem em seu projeto a premissa de proporcionar impactos mínimos ao entorno quando de sua implantação. É etiquetado com o Selo Procel em nível A de eficiência 
energética e possui certificação BREEAM In-Use nível excelente (SERVIÇO..., 2016).

Apesar dos empreendimentos citados buscarem melhorar seu desempenho ambiental, nenhum deles utilizou a ACV como metodologia de avaliação, o que confere caráter inovador à presente pesquisa no âmbito local.

Assim sendo, o objetivo geral é analisar os potenciais impactos ambientais da fase de construção de um edifício, considerando a contribuição dos sistemas construtivos de fundação, superestrutura, vedação, cobertura, esquadrias e revestimentos nas categorias de impacto ambiental, por meio da ACV, em uma abordagem de berço ao portão (grade-to-gate). Como objetivos específicos, pretende-se analisar o comportamento dos resultados quanto à adoção de diferentes métodos de AICV e verificar a qualidade dos dados de inventário, determinando a incerteza dos resultados obtidos em cada categoria.

\section{Método}

Como objeto de estudo para aplicação da ACV, buscou-se uma edificação pública com tecnologia e materiais construtivos comumente utilizados no estado de Mato Grosso. Selecionou-se, então, um edifício institucional de ensino público federal, construído na cidade de Primavera do Leste, MT, localizada a $240 \mathrm{~km}$ da capital Cuiabá, com área total de 4.347,57 $\mathrm{m}^{2}$, distribuída em pavimento térreo e pavimento superior, compreendendo bloco de salas de aula, setor administrativo, setor pedagógico, biblioteca, saguão e auditório.

A quantificação do inventário de fluxo de materiais da obra foi realizada a partir dos projetos arquitetônicos e estruturais que continham as especificações dos sistemas construtivos da edificação (Quadro 1).

Os princípios da ACV definidos na NBR ISO 14040 (ABNT, 2009a), NBR ISO 14044 (ABNT, 2009b) e detalhados no manual ILCD Handbook (EUROPEAN..., 2010) foram adotados como referencial metodológico em quatro fases: definição do objetivo e escopo, inventário do ciclo de vida (ICV), avaliação do impacto do ciclo de vida (AICV) e interpretação, a seguir descritas.

Quadro 1 - Descrição dos sistemas construtivos que compõem a edificação

\begin{tabular}{|c|c|c|}
\hline SISTEMAS & DESCRIÇÃO & $\begin{array}{c}\text { UNIDADES DE } \\
\text { QUANTIFICAÇÃO }\end{array}$ \\
\hline Fundação & $\begin{array}{l}\text { Fundações do tipo profunda, em estacas hélice } \\
\text { contínua monitorada, Ø33 cm e diferentes } \\
\text { tamanhos. }\end{array}$ & \multirow{2}{*}{$\begin{array}{l}\text { Cimento }(\mathrm{kg}) \text {, areia }\left(\mathrm{m}^{3}\right) \text {, } \\
\text { brita }\left(\mathrm{m}^{3}\right) \text {, aço }(\mathrm{kg}) \mathrm{e} \\
\text { madeira para formas } \\
\left(\mathrm{m}^{3}\right) .\end{array}$} \\
\hline Superestrutura & $\begin{array}{l}\text { Em concreto armado, composta por pilares, vigas e } \\
\text { lajes maciças. }\end{array}$ & \\
\hline Vedações & $\begin{array}{l}\text { Paredes externas e internas em tijolos cerâmicos de } \\
8 \text { furos, } 10 \mathrm{~cm} \text { x } 20 \mathrm{~cm} \text { x } 20 \mathrm{~cm} \text {, assentados de } 1 / 2 \\
\text { vez com argamassa de cimento, cal e areia no traço } \\
\text { em volume } 1: 2: 8 \text {. Chapisco com argamassa de } \\
\text { cimento e areia no traço em volume } 1: 3 \text {, espessura } \\
0,5 \mathrm{~cm} \text { nas paredes internas e externas. Emboço de } \\
\text { argamassa de cimento, cal e areia no traço em } \\
\text { volume } 1: 2: 8 \text {, espessura de } 2 \mathrm{~cm} \text {, nas paredes } \\
\text { internas e externas. }\end{array}$ & $\begin{array}{l}\text { Cimento }(\mathrm{kg}), \text { cal }(\mathrm{kg}) \text { e } \\
\text { areia }\left(\mathrm{m}^{3}\right) \text { para } \\
\text { argamassa, chapisco e } \\
\text { emboço e tijolos } \\
\text { cerâmicos }(\mathrm{kg}) .\end{array}$ \\
\hline Cobertura & $\begin{array}{l}\text { Cobertura em estrutura metálica, com telhas } \\
\text { termoacústicas de perfil trapezoidal, espessura de } 30 \\
\text { mm e altura de } 70 \mathrm{~mm} \text {, largura útil de } 1.000 \mathrm{~mm} \text {. }\end{array}$ & $\begin{array}{l}\text { Aço da estrutura }(\mathrm{kg}), \\
\text { telha termoacústica }\left(\mathrm{m}^{2}\right) \\
\text { e calhas e rufos }(\mathrm{kg}) . \\
\end{array}$ \\
\hline Esquadrias & $\begin{array}{l}\text { Janelas em alumínio anodizado e vidro } 4 \text { mm, } \\
\text { portas externas e internas, em madeira. }\end{array}$ & $\begin{array}{l}\text { Janelas de alumínio }(\mathrm{kg}) \text {, } \\
\text { vidro }(\mathrm{kg}) \text { e portas de } \\
\text { madeira }\left(\mathrm{m}^{2}\right) \text {. }\end{array}$ \\
\hline Revestimento & $\begin{array}{l}\text { Piso em granilite no bloco de sala de aulas e } \\
\text { administrativo e porcelanato na recepção, auditório } \\
\text { e biblioteca. Paredes das áreas molhadas revestidas } \\
\text { com cerâmica. }\end{array}$ & $\begin{array}{l}\text { Argamassa de } \\
\text { assentamento }(\mathrm{kg}), \\
\text { porcelanato }\left(\mathrm{m}^{2}\right), \\
\text { granillite }\left(\mathrm{m}^{2}\right) \text { e azulejos } \\
\text { cerâmicos }\left(\mathrm{m}^{2}\right) .\end{array}$ \\
\hline
\end{tabular}




\section{Descrição das fases da ACV \\ Definição do objetivo e escopo}

Segundo a NBR ISO 14040 (ABNT, 2009a), no objetivo e escopo de uma ACV, deve-se apresentar a aplicação pretendida, as justificativas, o público, e, ainda a finalidade dos resultados. No escopo, deve-se também englobar o sistema de produto, as funções, a unidade funcional, os limites de sistema, os procedimentos de alocação, as categorias de impacto e a metodologia de avaliação do impacto. Em ACV aplicada às edificações, a área construída bruta tem sido frequentemente utilizada como base de comparação e os valores absolutos dos impactos ambientais, fluxos e custos, dentre outros, costumam ser divididos pela área de construção (MALMQVIST; GLAUMANN, 2006).

Para o presente estudo, o objetivo da ACV consiste na contabilização dos potenciais impactos ambientais gerados pelo edifício objeto de estudo, do berço ao portão, ou seja, desconsiderando-se a fase de uso e fim de vida, abordando os processos construtivos de fundações, superestrutura, vedações, cobertura, esquadrias e revestimentos de piso e revestimentos de parede. Muito embora o tipo de fundação varie com o tipo de solo, o que impede generalizações, essa etapa construtiva foi considerada justificada pelo fato de consumir grande quantidade de cimento e aço; consequentemente, tem importância nos resultados de estudos como esse, conforme Livesey e Macé (2016) e Pacheco-Torres et al. (2014), que destacaram a relevância da etapa de fundação nos impactos ambientais do edifício.
Quanto ao contexto decisório, a ACV classifica-se como uma contabilização, ou seja, uma análise descritiva do ciclo de vida do edifício objeto de estudo.

A função deste estudo é analisar um edifício construído com materiais de construção usualmente empregados.

A unidade funcional adotada é de $1,0 \mathrm{~m}^{2}$ de área construída. Quanto ao fluxo de referência, este consiste na quantidade total dos materiais necessários para a construção do edifício objeto de estudo.

A fronteira do sistema determina quais processos elementares e quais partes do ciclo de vida serão investigadas na ACV (Figura 1). Sua definição clara e precisa é essencial para garantir que todos os processos atribucionais sejam incluídos na modelagem. É obrigatório que as fronteiras do sistema sejam representadas por diagrama, no qual constem as partes e estágios do ciclo de vida do sistema que fazem parte do estudo e quais são excluídas (EUROPEAN..., 2010). Para este estudo, o critério de corte adotado foi o fluxo de massa, excluindo-se do inventário as entradas que não atingem o valor mínimo de $0,1 \%$ da massa total de entradas do sistema. A definição do valor de corte baseou-se nos estudos de Bueno et al. (2016).

\section{Inventário do ciclo de vida (ICV)}

Segundo a NBR ISO 14040 (ABNT, 2009a), na fase do ICV registram-se todos os fluxos de entrada e saída dos processos, fluxos de produtos, de resíduos e outras informações de produção identificadas como relevantes.

\section{Figura 1 - Fronteira do sistema}

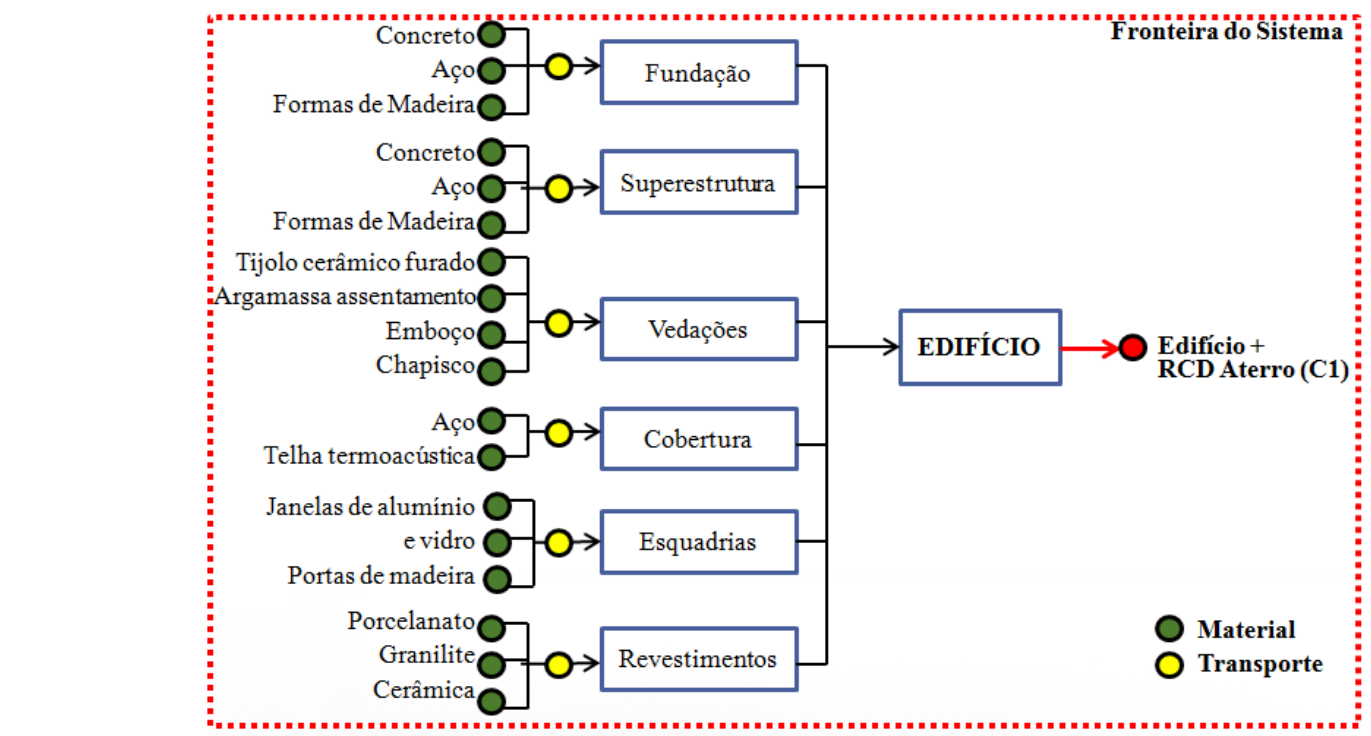

Fonte: Medeiros (2016). 
No presente estudo, a estruturação da coleta de dados para o inventário foi adaptada dos processos incluídos nas fases de produção e construção consideradas pela EN 15978 (BRITISH..., 2011), mapeando os processos envolvidos na fase de construção. Foram considerados o transporte dos materiais da indústria até o canteiro de obra e os impactos incorporados nos próprios materiais, de acordo com o banco de dados Ecoinvent. Não foi considerada neste estudo a energia consumida durante a fase de construção, nem o transporte de funcionários, por ausência de registros desses consumos.

A partir dos projetos executivos e dos quantitativos dos projetos arquitetônico e estrutural, totalizaramse os materiais dos sistemas de fundação, superestrutura, vedações, cobertura, esquadrias e revestimentos para a área total da edificação de $4.347,57 \mathrm{~m}^{2}$.

Para a modelagem, buscaram-se os processos no banco de dados Ecoinvent, preferencialmente os modelados com a matriz energética brasileira. Nos casos de inexistência, os processos foram modelados de maneira simplificada, com base nas composições analíticas do Sistema Nacional de Pesquisa de Custos e Índices da Construção Civil (Sinapi), conforme a Caixa Econômica Federal (2016).

Os dados inventariados foram transformados em valores de massa (kg). Para os processos do Ecoinvent, foram adotados os valores de densidade nele constante, e para os processos modelados a partir do Sinapi, a densidade da água foi obtida de Lopes (2011) e das telhas termoacústicas de Isoeste (2016).

As distâncias dos transportes somam o trajeto de ida e volta da origem do material até o local da obra. As distâncias consideradas na aquisição dos materiais foram de $15 \mathrm{~km}$, para os adquiridos na própria cidade da obra. As demais distâncias foram de 90 km, 510 km, 714 km, 1.320 km e 3.000 km, para as cidades de Poxoréu, Cuiabá, Nobres, Goiânia e São Paulo, respectivamente, estimadas por meio do Google Maps ${ }^{1}$.

Dessa forma, foram construídas as tabelas de inventário, que apresentam os quantitativos da obra analisada e sua correlação com a unidade funcional.

\section{Avaliação do impacto do ciclo de vida (AICV)}

Nessa fase da ACV, são analisados os resultados obtidos do inventário. Os dados coletados são convertidos em indicadores de impactos relacionados às categorias de impacto ambiental descritas na concepção do escopo (EUROPEAN..., 2010).

Conforme Mendes, Bueno e Ometto (2013), os métodos de AICV se dividem em três níveis de avaliação: pontos médios (midpoint), de extremidade (endpoint) e análise nos dois níveis. Destes, os mais utilizados e discutidos em ACV de edificações são: Eco-indicator 99, EDIP 97-2003, CML 2002, Impact 2002+, ReCiPe e IMPACT World+.

Segundo Costa (2012), no Brasil os métodos midpoint e endpoint mais utilizados são o CML 2002 e o Eco-indicator 99, respectivamente, devido a dois aspectos principais: abrangência global das categorias consideradas, em conformidade com as características do meio ambiente brasileiro, e a atribuição de pesos e notas no cálculo baseada em índices mundiais. Contudo, o método ReCiPe consiste na continuação dos métodos Eco-indicador 99 e CML 2002, sendo o mais recomendado atualmente.

Segundo Bueno et al. (2016), as metodologias midpoint determinam um número maior de categorias de impacto, apresentando resultados mais exatos e precisos em comparação com avaliações endpoint, que, normalmente, consideram apenas três áreas de proteção (saúde humana, qualidade do ecossistema e uso de recursos). Por essa razão, a metodologia midpoint foi adotada neste estudo.

Considerando que a ACV em edificações envolve a manipulação de um grande volume de informações e dados, faz-se necessária a utilização de ferramentas computacionais que possibilitem a organização e garantam maior confiabilidade no processamento dos dados, existindo no mercado diversos softwares para essa finalidade (RODRIGUES et al., 2008).

Dentre esses softwares, citam-se o System for Integrated Environmental Assessment of Products (SimaPro) (NASCIMENTO, 2011; SANSÃO, 2011; MACEDO, 2011; LOPES, 2011; SAADE, 2013; OLIVEIRA, 2013), o GaBi 4.0 (BUENO et al., 2016; SILVA, 2015) e o Umberto (CAMPOS, 2012).

No presente estudo, para correlação dos resultados do ICV às categorias de impacto selecionadas (classificação) e cálculo dos resultados dos indicadores de categoria (caracterização) utilizouse o software SimaPro 8.0. Para cada categoria de impacto ambiental foi aprofundada a avaliação nos dois sistemas que apresentaram maior contribuição

1Disponível em: বttps:// www.google.com.br/maps>. 
e nestes foram identificados os processos envolvidos, apresentando os resultados a partir de uma linha de corte de 3\%, o que possibilitou uma visualização dos que mais contribuem para o impacto identificado. Os resultados são apresentados para a unidade funcional definida de $1,0 \mathrm{~m}^{2}$ de área construída do edifício.

\section{Interpretação}

Com base na pesquisa de Mendes, Bueno e Ometto (2013) foram selecionadas para este estudo as categorias de impacto midpoint que vêm sendo tradicionalmente abordadas pela maioria dos métodos: mudanças climáticas ou aquecimento global, depleção da camada de ozônio, toxicidade humana, formação de material particulado, depleção da água, depleção de metais e depleção fóssil.

Nessa etapa de interpretação, realizou-se a identificação das questões significativas, a avaliação da completeza, por meio da análise de sensibilidade e análise de incerteza, e foram apresentadas as conclusões e limitações.

Segundo a NBR ISO 14044 (ABNT, 2009b), a análise de sensibilidade é um procedimento para verificar como os resultados de um estudo se comportam diante de mudanças nos dados de entrada, estimando o quanto essa mudança pode interferir no perfil ambiental ou em outro resultado da ACV. Consiste na variação de parâmetros, modelos ou métodos utilizados e na verificação de como os resultados finais se comportam, e avaliação das alternativas, o que ajuda a entender a magnitude dos efeitos das suposições realizadas (BENEDET JUNIOR, 2007).

Buscou-se verificar se a mudança do método de AICV alteraria os resultados para categorias semelhantes. Por isso, o método CML foi utilizado para comparar as categorias de mudanças climáticas, depleção do ozônio e toxicidade humana, que são as categorias comuns em ambos os métodos e apresentam resultado na mesma unidade de medida.

A análise de incerteza consiste em uma técnica específica para análise de qualidade dos dados da AICV e garante maior confiabilidade ao resultado do estudo. Essa análise foi realizada por meio do método conhecido como Matriz de Qualidade dos Dados (Matriz Pedigree), combinada com o método estatístico de Monte Carlo, para calcular a incerteza absoluta.

A Matriz Pedigree é composta por seis indicadores de qualidade de dados: confiança na fonte, completeza, correlação temporal, correlação geográfica, correlação tecnológica e número de amostra. Para cada indicador foi atribuída uma pontuação de 1 a 5 , sendo 1 o maior grau de qualidade e 5 o de pior qualidade. O último indicador referente ao tamanho da amostra caiu em desuso e o próprio software SimaPro 8.0 não exige atribuição de seu valor quando da construção da matriz.

Ao final do resultado da matriz, verifica-se o valor da incerteza básica relativo às entradas e saídas para diferentes fluxos elementares (aspecto ambiental) considerados para emissões de combustão, emissão de processos e emissões na agricultura. De posse desses resultados, foi possível calcular o desvio padrão ou grau de incerteza, para um intervalo de confiança de 95\%, mediante o uso da distribuição lognormal da Equação 1, assumida pelo Ecoinvent (PRÉ CONSULTANTS, 2016).

$\left.\left.\left.\left.\left.\left.D P=\sqrt[\exp ]{[\ln (u 1)]^{2}+} \ln (u 2)\right]^{2}+\ln (u 3)\right]^{2}+\ln (u 4)\right]^{2}+\ln (u 5)\right]^{2}+\ln (u 6)\right]^{2}+\ln (u b)\right]^{2}$

Eq. 1

Onde:

DP = Desvio padrão relativo;

$\mathrm{U} 1$ = Fator de incerteza do indicador confiança na fonte;

$\mathrm{U} 2$ = Fator de incerteza do indicador completeza;

U3 = Fator de incerteza do indicador correlação temporal;

U4 = Fator de incerteza do indicador correlação geográfica;

U5 = Fator de incerteza do indicador correlação tecnológica;

U6 = Fator de incerteza do indicador número de amostras; e

UB = Fator básico de incerteza.

A partir dos resultados verificados com o preenchimento da Matriz Pedigree e aplicação da equação foi possível utilizar a estatística de Monte Carlo para calcular a incerteza absoluta, que é a mais utilizada nos estudos de ACV. Essa análise estatística está disponível no software SimaPro 8.0, versão Analyst.

\section{Resultados e discussões}

\section{Análise de contribuição}

Esta análise buscou identificar a contribuição de cada um dos sistemas construtivos nas categorias de impacto ambiental investigadas. Os resultados demonstram que a superestrutura é o sistema que contribui com maior valor em quatro das sete categorias analisadas: mudanças climáticas, formação de material particulado, depleção de água e depleção fóssil (Tabela 1 e Figura 2). 
O sistema cobertura é o que apresenta maior valor em duas das sete categorias: toxicidade humana e depleção de metais. O sistema vedação é o que mais contribui para a categoria de depleção do ozônio.

O sistema esquadrias, seguido pelo revestimento, são os que menos contribuem em todas as categorias, devido à baixa representatividade em massa no edifício em estudo.

Na categoria de mudanças climáticas, para a unidade funcional de $1,0 \mathrm{~m}^{2}$ de área construída, obteve-se o valor de $353 \mathrm{kgCO}_{2} \mathrm{eq}$, valor que se aproxima do encontrado por Pacheco-Torres et al. (2014), a saber, $385 \mathrm{kgCO}_{2}$ eq por metro quadrado de área de superfície.
A partir dessas informações, são apresentadas, para cada categoria de impacto ambiental, as contribuições de cada sistema na unidade funcional de $1,0 \mathrm{~m}^{2}$ de área construída e, para os dois mais impactantes, são detalhadas as contribuições dos processos.

\section{Mudanças climáticas}

A análise das contribuições na categoria de mudanças climáticas, para a unidade funcional de 1,0 $\mathrm{m}^{2}$ de área construída, demonstrou que os sistemas superestrutura e vedação foram os que apresentaram maiores emissões: $125,67 \mathrm{kgCO}_{2}$ eq e 82,55 kgCO eq, respectivamente (Figuras 3 e 4).

Tabela 1 - Contribuições totais dos sistemas em cada categoria de impacto ambiental, para unidade funcional de 4.347,57 $\mathrm{m}^{2}$ de área construída

\begin{tabular}{|c|c|c|c|c|c|c|c|}
\hline Componentes & $\begin{array}{c}\text { Aquecimento } \\
\text { Global (CML) } \\
(\mathrm{GWP100)} \\
\left(\mathrm{kg} \mathrm{CO}_{2} \text { eq) }\right.\end{array}$ & $\begin{array}{c}\text { Depleção do } \\
\text { Ozônio }\end{array}$ & $\begin{array}{c}\text { Toxicidade } \\
\text { Humana }\end{array}$ & $\begin{array}{c}\text { Formação } \\
\text { de Material } \\
\text { Particulado } \\
\text { (kg PM10 eq) }\end{array}$ & $\begin{array}{c}\begin{array}{c}\text { Depleção da } \\
\text { água }\end{array} \\
\left(\mathrm{m}^{3}\right)\end{array}$ & $\begin{array}{c}\text { Depleção de } \\
\text { Metais } \\
\text { (kg Fe eq) }\end{array}$ & $\begin{array}{l}\text { Depleção } \\
\text { Fóssil } \\
\text { (kg oil eq) }\end{array}$ \\
\hline FUNDAÇÃO & $265.770,17$ & 0,01 & $16.786,43$ & 777,64 & $2.802,94$ & $15.693,85$ & $35.812,17$ \\
\hline SUPERESTRUTURA & $546.362,25$ & 0,03 & 72.123,81 & $2.344,64$ & $5.506,55$ & $88.004,46$ & $99.739,82$ \\
\hline VEDAÇÃO & $358.905,34$ & 0,03 & $11.328,46$ & 348,10 & $2.274,95$ & $9.341,88$ & $74.697,02$ \\
\hline COBERTURA & $210.472,80$ & 0,01 & 283.602,89 & 727,69 & $4.438,51$ & $168.294,10$ & $58.734,38$ \\
\hline ESQUADRIAS & $49.009,97$ & 0,00 & $7.444,82$ & 104,48 & 242,86 & $3.437,85$ & $14.066,53$ \\
\hline REVESTIMENTO & 98.233,99 & 0,01 & $6.782,64$ & 135,57 & 451,72 & $4.131,24$ & $32.045,69$ \\
\hline
\end{tabular}

Fonte: Medeiros (2016).

Figura 2 - Análise das contribuições totais dos sistemas em cada categoria de impacto ambiental, para unidade funcional de $4.347,57 \mathrm{~m}^{2}$ de área construída

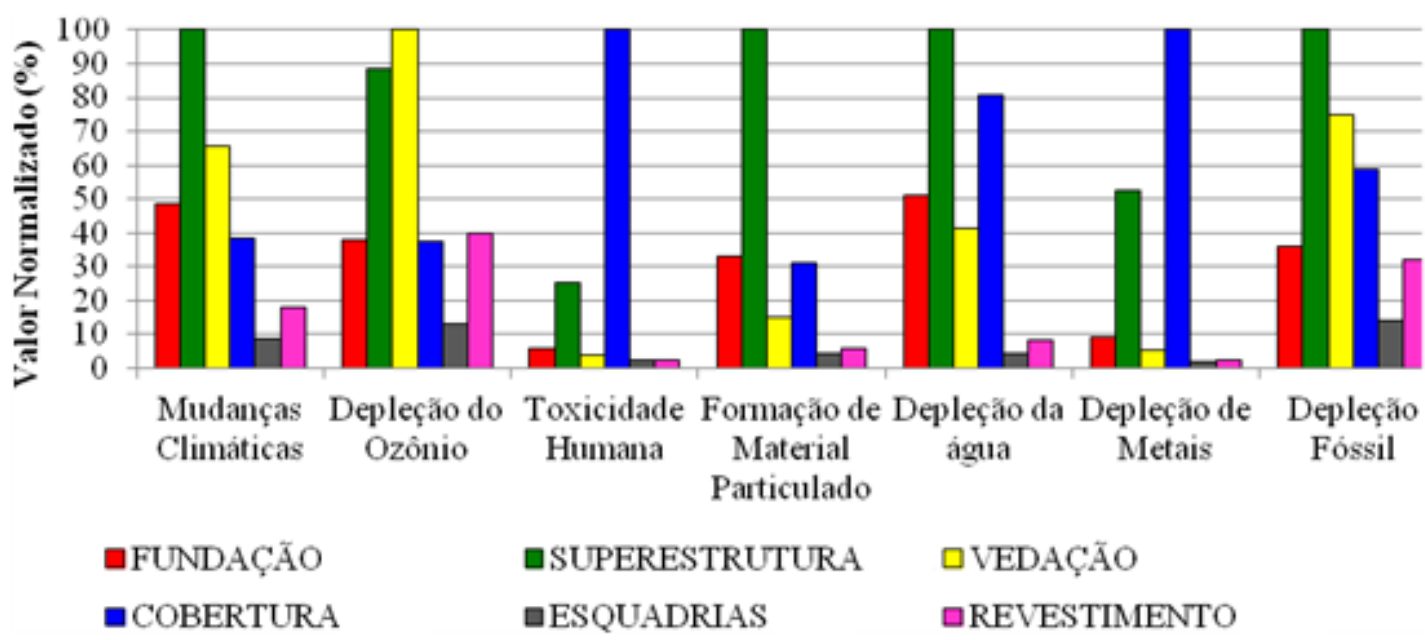

Fonte: Medeiros (2016). 
Figura 3 - Contribuição dos processos no sistema de superestrutura para mudanças climáticas (unidade funcional de $1,0 \mathrm{~m}^{2}$ de área construída)

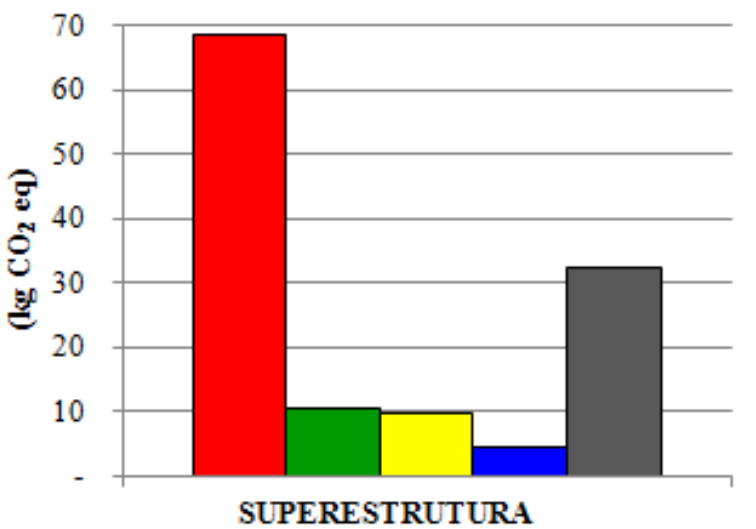

- Clinker, at plant/CHU

-Pigiron, at plant/GLO U

$\square$ Diesel, burned in building machine/GLOU

- Electricity, hydropower, at reservoir power plant/BRU

口Remaining processes

Fonte: Medeiros (2016)

Figura 4 - Contribuição dos processos no sistema de vedação para mudanças climáticas (unidade funcional de $1,0 \mathrm{~m}^{2}$ de área construída)

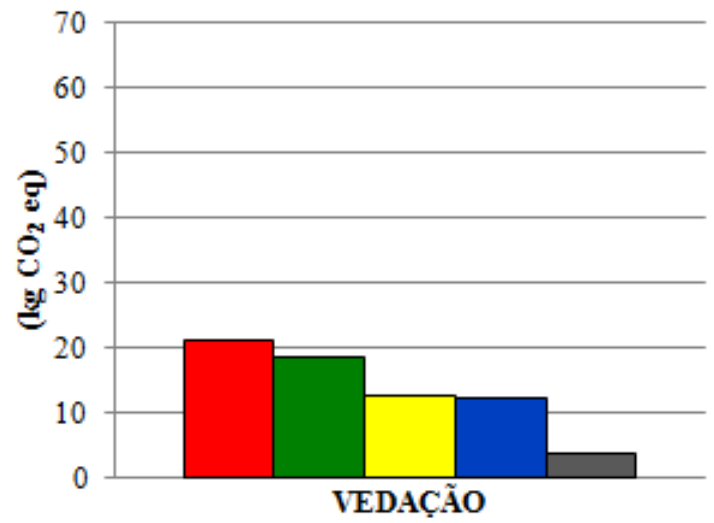

- Clinker, at plant/CHU

$\square$ Brick, at plant/RERU Energia $B R$

$\square$ Quicklime, in pieces, loose, at plant/CHU

Operation, lorry 16-32t, EURO3/RER U

$\square$ Light fuel oil, burned in industrial furnace $1 \mathrm{MW}$, non-modulating/CHU

Fonte: Medeiros (2016).

Ao analisar os processos em ambos os sistemas, o que apresentou maior contribuição foi o de produção de clínquer (clinker, at plant/CH U), responsável por altas emissões de gases de efeito estufa (GEE), principalmente o dióxido de carbono $\left(\mathrm{CO}_{2}\right)$ e metano $\left(\mathrm{CH}_{4}\right)$. Esses resultados corroboram com WBCSD (2002 2 apud MAURY; BLUMENSCHEIN, 2012), quando citam que na produção do Cimento Portland (CP), 40\% das emissões são provenientes do processo de clinquerização. Para a produção de uma tonelada de clínquer são emitidos cerca de $900 \mathrm{kgCO}_{2}$, contribuindo para que a indústria do cimento seja responsável por $5 \%$ a $7 \%$ das emissões mundiais de $\mathrm{CO}_{2}$ (SUMNER; GIANETTI; BENINI, 2008).

O segundo processo que mais contribuiu foi o de fabricação de tijolos cerâmicos, também devido às

${ }^{2}$ WORLD BUSINESS COUNCIL FOR SUSTAINABLE DEVELOPMENT Toward a Sustainable Cement Industry: substudy 8 , climate altas emissões de $\mathrm{CO}_{2}$ provenientes do processo de queima de combustíveis.

Os processos identificados como de maior contribuição são os mesmos identificados nos trabalhos de Campos (2012) e de Bueno et al. (2016). Bueno et al. (2016) chegaram a um resultado de $140 \mathrm{kgCO}_{2}$ eq para $1,0 \mathrm{~m}^{2}$ de alvenaria. No presente estudo, verificou-se um valor de 82,55 $\mathrm{kgCO}_{2}$ eq para $1,0 \mathrm{~m}^{2}$ de área construída. Como as unidades funcionais são diferentes, não se pode estabelecer uma comparação entre esses valores.

\section{Depleção do ozônio}

Os sistemas que mais contribuíram com essa categoria de impacto, para unidade funcional de 1,0 $\mathrm{m}^{2}$ de área construída, foram vedação, com uma emissão de 6,88E-06 kg CFC-11eq, e

change. Eds. Ken Humphreys and Maha Mahasenan. WBCSD, 2002. 
superestrutura, emitindo 6,09E-06 kg CFC-11 eq (Figuras 5 e 6).

Ao analisar as contribuições em ambos os sistemas (vedação e superestrutura), o processo que apresentou maior contribuição foi o de extração de petróleo (crude oil, at production onshore/RAF $U$ ), principalmente devido à emissão de gases Halon 1301 e Halon 1211 na atmosfera.

Esses gases são utilizados na prevenção de incêndios, em locais de extração, para garantir a segurança do processo (HANSEN, 2013). Os gases Halon 1301 e Halon 1211 estão inventariados no processo de extração de petróleo internacional; porém, no Brasil, segundo o Ministério de Meio Ambiente, esses gases não são mais utilizados desde 2010 (MINISTÉRIO..., 2009).
Neste estudo, foi inventariado o transporte de materiais de acordo com a realidade local da obra, que em seu ciclo de vida considera a extração de petróleo da base de dados Ecoinvent, com os gases acima citados. Portanto, em trabalhos futuros, cabe um aprofundamento para a realidade da produção brasileira de petróleo.

\section{Toxicidade humana}

A avaliação de impacto para essa categoria, para unidade funcional de 1,0 $\mathrm{m}^{2}$ de área construída, demonstra uma contribuição consideravelmente maior para o sistema de cobertura, com uma emissão de 65,23 kg 1,4-DB eq, seguida pelo sistema de superestrutura, que emite $16,59 \mathrm{~kg} 1,4-$ DB eq.

\section{Figura 5 - Contribuição dos processos no sistema de vedação para depleção do ozônio (unidade funcional de $1,0 \mathrm{~m}^{2}$ de área construída)}

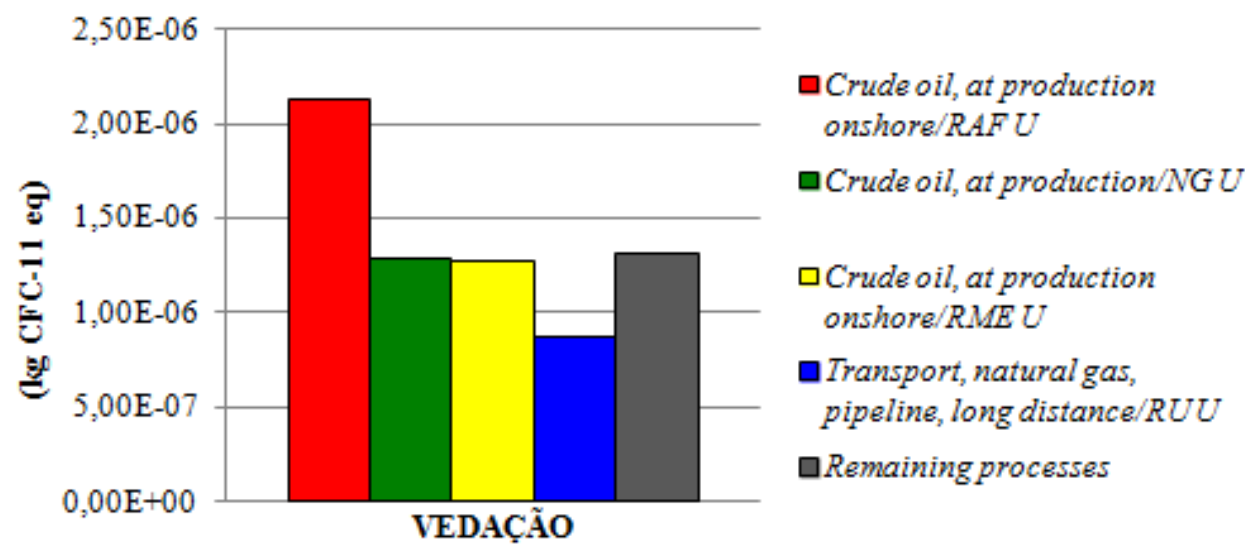

Fonte: Medeiros (2016).

Figura 6 - Contribuição dos processos no sistema de superestrutura para depleção do ozônio (unidade funcional de 1,0 $\mathrm{m}^{2}$ de área construída)

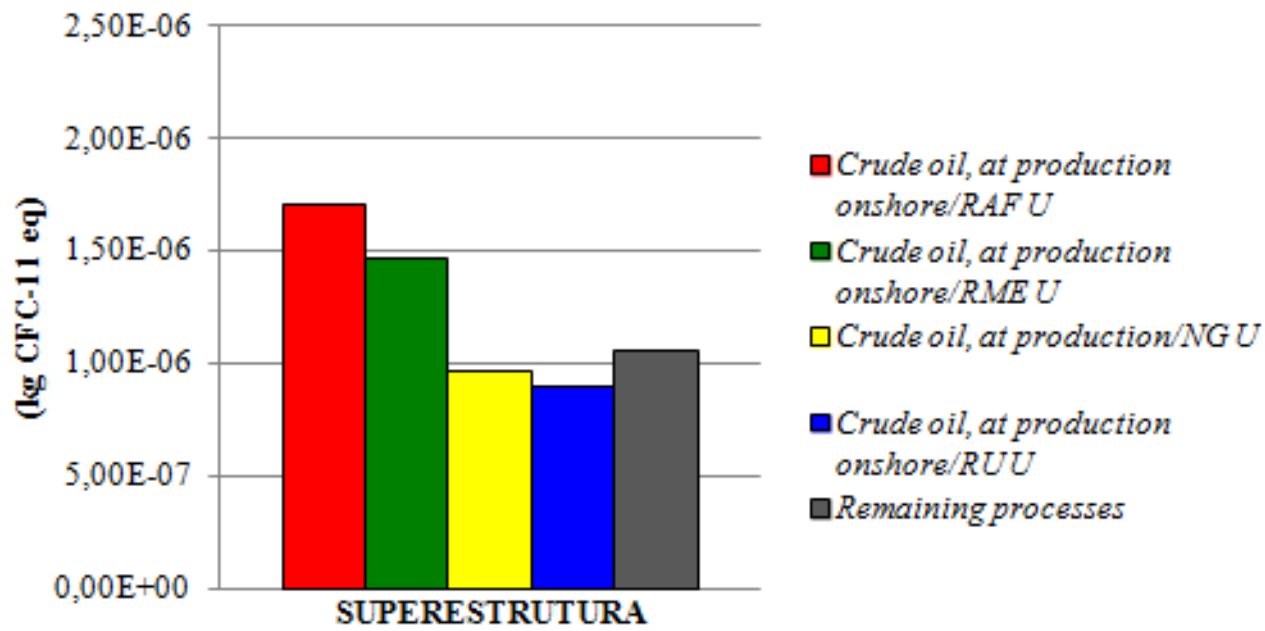

Fonte: Medeiros (2016). 
Analisando a Figura 7 de contribuição do sistema de cobertura, verifica-se que o processo de produção da telha metálica (zinc, prymary, at regional storage/RER $U$ ) foi o que apresentou maior emissão de $\mathrm{kg}$ 1,4-DB equivalentes. Isso se deve as emissões de substâncias tais como: fósforo, arsênio, bário e cádmio.

A Figura 8 apresenta os processos que contribuem para o sistema de superestrutura, na qual se verifica que a produção do aço de liga leve (steel, electric, un-and low-alloyed, at plant/ RER $U$ ) representa a maior contribuição, devido às emissões de substâncias como mercúrio, zinco e cádmio.

Considerando que os fatores inerentes à caracterização dessa categoria são relacionados a produtos químicos, dos quais ainda há pouco conhecimento disponível, as conclusões são acompanhadas por incertezas maiores do que em categorias consolidadas como, por exemplo, a de aquecimento global (EUROPEAN..., 2010). Portanto, há que se ponderar nas conclusões obtidas na categoria de toxicidade humana.
Cabe aqui destacar que Bueno et al. (2016) usaram o percentual de reciclagem do aço de $24 \%$ a partir de informações de agências brasileiras e também identificou o processo de produção do aço como o maior contribuinte para a categoria de toxicidade humana. O percentual de reciclagem do aço adotado neste estudo é o constante da base de dados Ecoinvent, já que o processo de produção do aço não foi modelado.

\section{Formação de material particulado}

Os sistemas que mais contribuíram para essa categoria, para unidade funcional de $1,0 \mathrm{~m}^{2}$ de área construída, foram a superestrutura, com emissão de 0,54 kg PM10eq, e a fundação, que emitiu 0,18 kg PM10eq (Figuras 9 e 10).

A contribuição das fôrmas de madeira (roundwood, Paraná pine (SFM, under bark, $u=50 \%$, at Forest $R o a d / B R U$ ) foi superior aos demais processos, em ambos os sistemas. O potencial de impacto das fôrmas de madeira é proveniente das etapas de serragem, produção das toras e do consumo de combustíveis nos processos.

Figura 7 - Contribuição dos processos no sistema de cobertura para toxicidade humana (unidade funcional de $1,0 \mathrm{~m}^{2}$ de área construída)

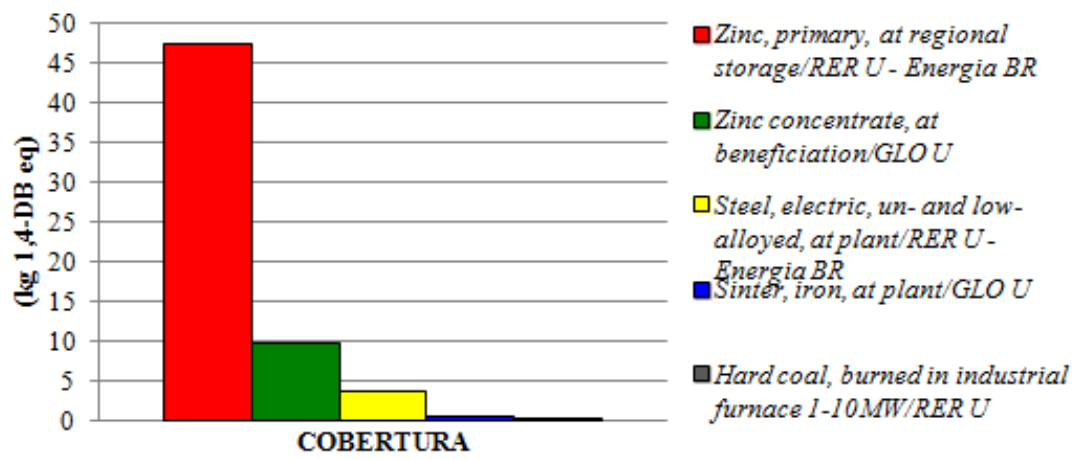

Fonte: Medeiros (2016)

Figura 8 - Contribuição dos processos no sistema de superestrutura para toxicidade humana (unidade funcional de $1,0 \mathrm{~m}^{2}$ de área construída)

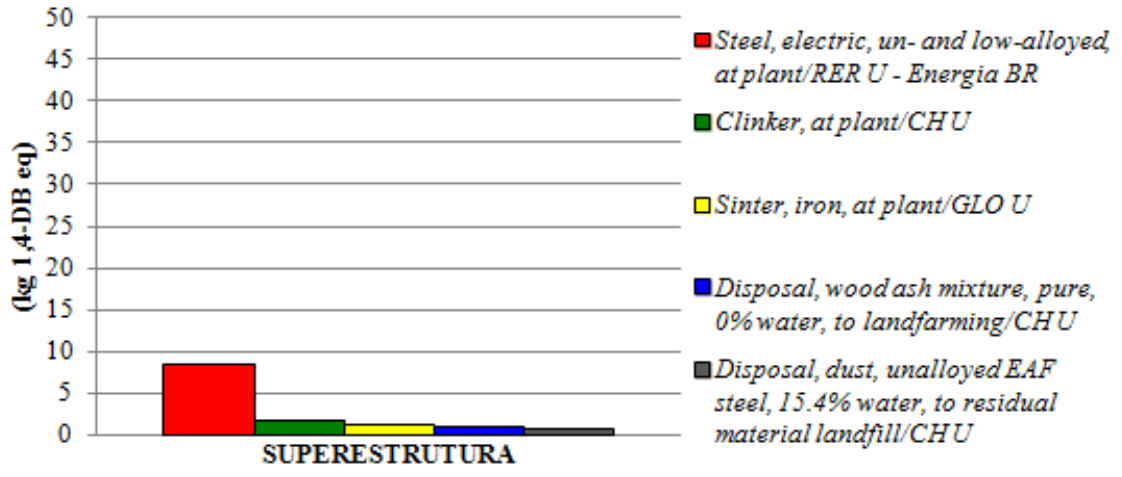

Fonte: Medeiros (2016). 
Figura 9 - Contribuição dos processos no sistema de superestrutura para formação de material particulado (unidade funcional de $1,0 \mathrm{~m}^{2}$ de área construída)

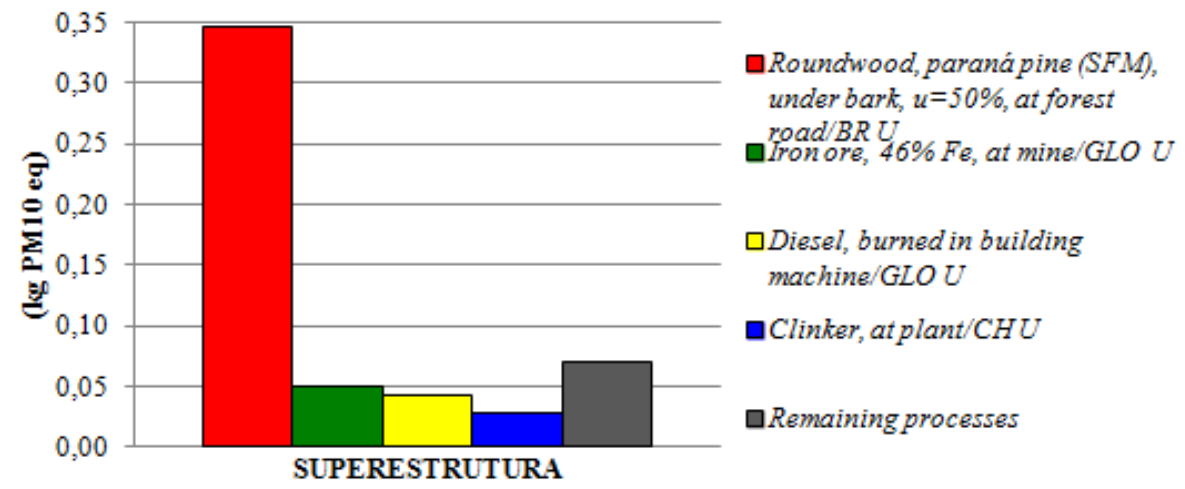

Fonte: Medeiros (2016).

Figura 10 - Contribuição dos processos no sistema de fundação para formação de material particulado (unidade funcional de $1,0 \mathrm{~m}^{2}$ de área construída)

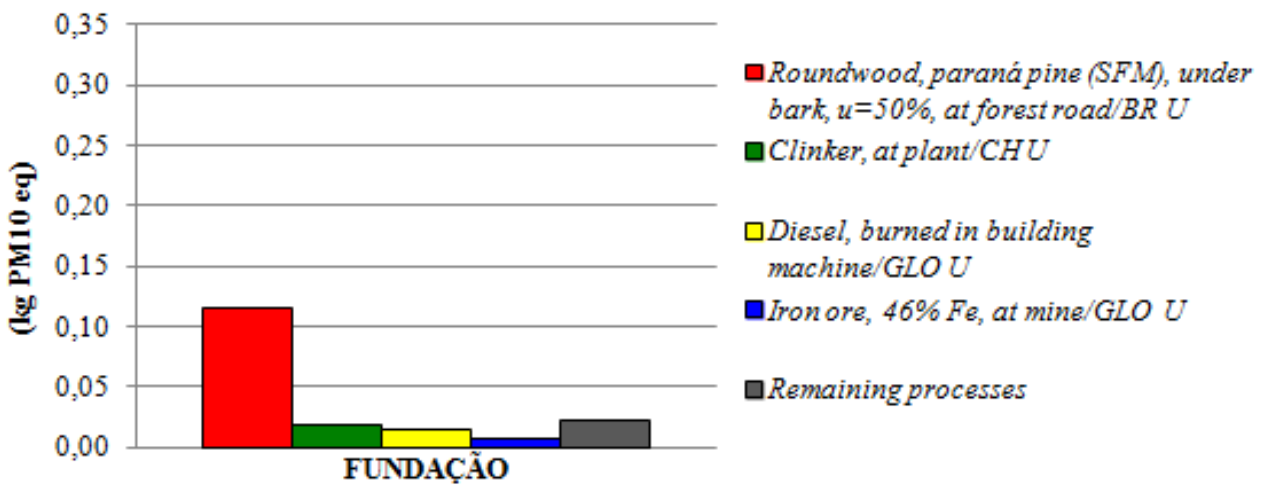

Fonte: Medeiros (2016).

Segundo Fagundes (2003), a produção das toras de madeira apresenta potencial impacto para diversas categorias. Após o corte, a árvore é desgalhada e traçada em toras, e essa etapa consome uma grande quantidade de diesel nas máquinas; por sua vez a queima do diesel emite diversos poluentes, como gases de efeito estufa $\left(\mathrm{CO}_{2}, \mathrm{CO}, \mathrm{NOx}, \mathrm{SO}_{2}\right)$, além de materiais particulados e compostos orgânicos voláteis.

\section{Depleção da água}

Os sistemas que mais contribuíram com essa categoria, para unidade funcional de 1,0 $\mathrm{m}^{2}$ de área construída, foram a superestrutura e a cobertura, com consumos de $1,27 \mathrm{~m}^{3}$ e $1,02 \mathrm{~m}^{3}$, respectivamente.

O consumo de água no sistema de superestrutura (Figura 11) está ligado diretamente à produção do concreto. Segundo Rossi (2013), no ciclo de vida da brita (gravel, round, at mine/ $C H U$ ), a água é consumida em três etapas, uma para nebulização de vias durante o transporte ao beneficiamento, a segunda durante o próprio processo de beneficiamento para melhorar o desempenho da britagem e não promover o acúmulo de pó, e a terceira etapa, a qual apresenta o maior consumo, é a fase de uso da brita, ou seja, a sua utilização como agregado no processo de produção do concreto.

No sistema de cobertura (Figura 12), o processo de beneficiamento do zinco (zinc, primary, at regional storage/RER $U$ ) é o que apresenta maior consumo na categoria.

\section{Depleção de metais}

Na categoria de depleção de metais, para unidade funcional de 1,0 $\mathrm{m}^{2}$ de área construída, os sistemas que mais contribuem são a cobertura, consumindo $38,71 \mathrm{~kg} F e$ eq, e a superestrutura, consumindo 20,24 kg Fe eq (Figuras 13 e 14).

No sistema de cobertura (Figura 13), o consumo de metais está associado à produção das telhas metálicas que compõem a cobertura termoacústica. Esse sistema apresenta alto grau de incerteza, já que não se localizou no banco de dados Ecoinvent um processo para esse produto e adotou-se uma modelagem simplificada. 
No sistema de superestrutura (Figura 14), o processo que mais contribuiu está ligado à produção de aço. Analisando a origem do potencial impacto verifica-se que está associado ao consumo de minério de ferro (iron, $46 \% \mathrm{Fe}$, at mine/ GLO U). Além disso, a produção de coque, adição do cromo, molibdênio e níquel também contribuem (SILVA; YOKOTE; RIBEIRO, 2002).

Cabe, também, para essa categoria, a consideração feita por Bueno et al. (2016) de que tais impactos poderiam ser mitigados pelo aumento dos percentuais de reciclagem do produto.

Figura 11 - Contribuição dos processos no sistema de superestrutura para depleção de água (unidade funcional de $1,0 \mathrm{~m}^{2}$ de área construída)

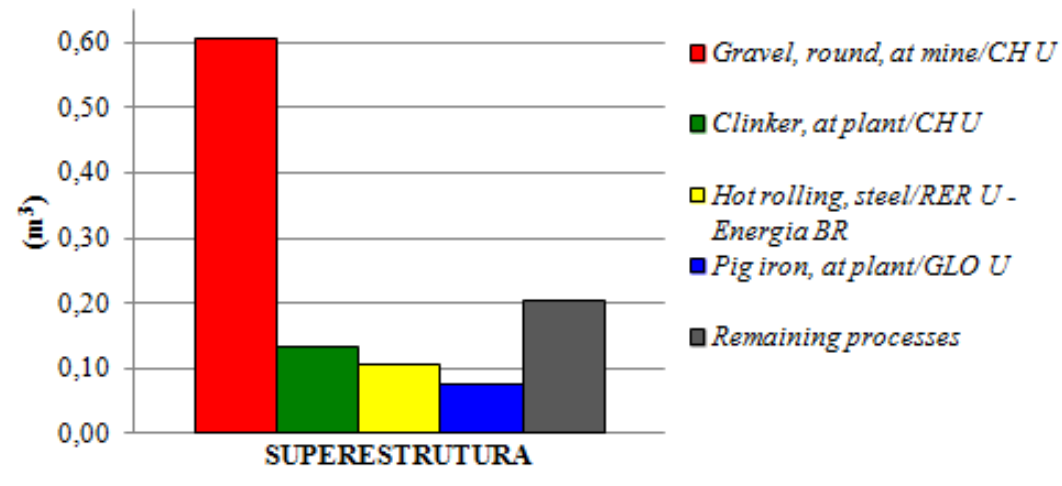

Figura 12 - Contribuição dos processos no sistema de cobertura para depleção de água (unidade funcional de $1,0 \mathrm{~m}^{2}$ de área construída)

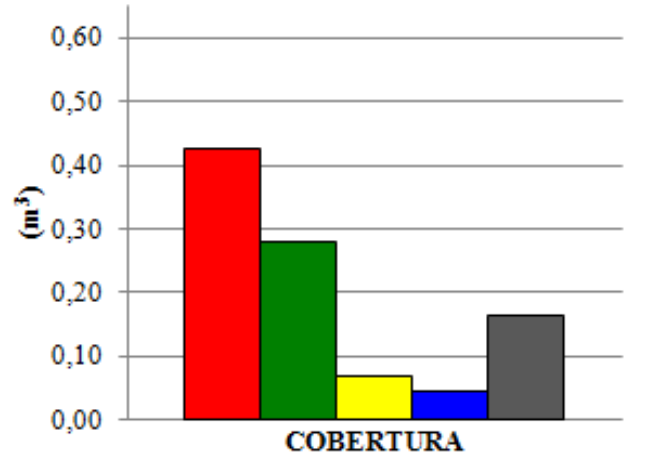

$\square$ Zinc, primary, at regional storage/RER U-Energia BR

$\square$ Zinc concentrate, at beneficiation/GLOU

$\square$ Sand, at mine/CH U

Hot rolling, steel/RER U Energia $B R$

$\square$ Remaining processes

Figura 13 - Contribuição dos processos no sistema de cobertura para depleção de metais (unidade funcional de $1,0 \mathrm{~m}^{2}$ de área construída)

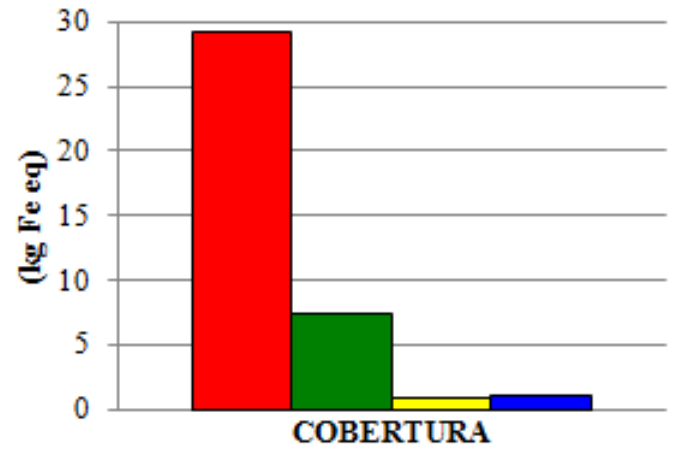

\author{
$\square$ Zinc concentrate, at \\ beneficiation/GLOU \\ aronore, $46 \% \mathrm{Fe}$, at \\ mine/GLO $U$ \\ ㅁ Ferronickel, 25\% Ni, at \\ plant/GLOU \\ - Remaining processes
}

Fonte: Medeiros (2016). 
Figura 14 - Contribuição dos processos no sistema de superestrutura para depleção de metais (unidade funcional de $1,0 \mathrm{~m}^{2}$ de área construída)

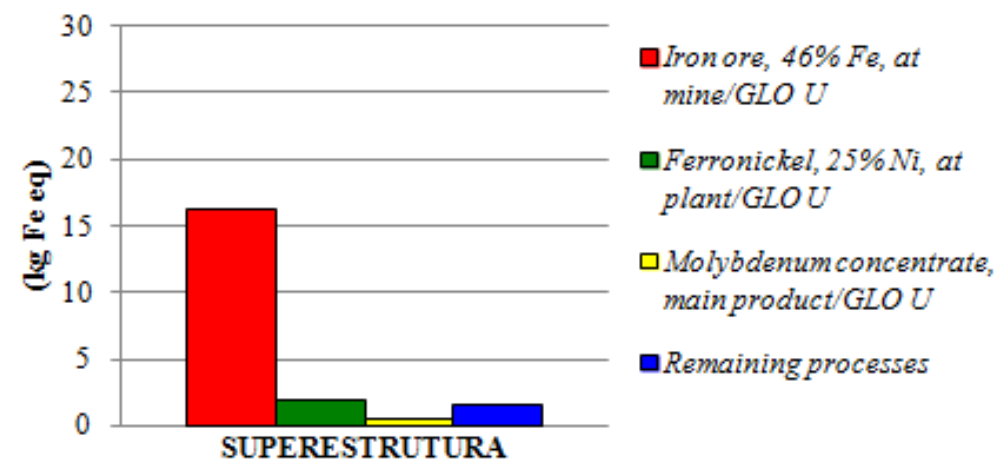

Fonte: Medeiros (2016)

\section{Depleção fóssil}

Na categoria de depleção fóssil, para unidade funcional de 1,0 $\mathrm{m}^{2}$ de área construída, os sistemas que mais contribuem são a superestrutura, com consumo de 22,94 kg óleo eq, e a vedação, que consome 17,18 kg óleo eq. (Figuras 15 e 16).

No sistema de superestrutura, o consumo de recursos fósseis aparece, principalmente, nos processos de fabricação do concreto e do aço. Investigando-se a origem principal desse consumo, identificou-se que está relacionado ao consumo de carvão mineral (hard coal, at mine/WEU U).

No sistema de vedação, o maior consumo está ligado à produção de argamassa de emboço, seguido do transporte. A origem dos impactos se dá pelo consumo de petróleo (crude oil, at prodution onshore/ $R A F U$ ) na fabricação de cal hidratada e cimento Portland, bem como no uso de combustível diesel para o transporte.

\section{Análise de sensibilidade}

A análise de contribuição foi realizada pelo método ReCiPe e, para verificar a sensibilidade dos resultados à aplicação de outros métodos de AICV, aplicou-se outra metodologia de AICV, o CML 2 Baseline, limitando a análise as categorias comuns aos dois métodos: mudanças climáticas e aquecimento global, depleção do ozônio e toxicidade humana. A análise foi realizada para a mesma unidade funcional de $1,0 \mathrm{~m}^{2}$ de área construída.

A Figura 17 apresenta a comparação dos resultados nos dois métodos de AICV, e a Tabela 2 os valores de cada sistema para cada uma das categorias comparadas.

Verifica-se nos resultados que apesar de existir ligeira mudança de valores isso não altera 0 ranqueamento dos sistemas nas categorias, ou seja, os sistemas mais contributivos permanecem os mesmos em ambas as metodologias de AICV.

Os resultados para as categorias de mudanças climáticas e depleção do ozônio mostram-se bastantes consistentes, o que demonstra que, independentemente da metodologia de AICV aplicada, os sistemas de superestrutura e de vedação permanecem sendo os maiores contribuintes para cada categoria, respectivamente.

A categoria de toxicidade humana foi a que apresentou maior variação, ainda que o sistema mais significativo tenha permanecido o mesmo. Isso se deve ao fato de que cada um dos métodos de AICV avalia a toxicidade humana utilizando-se de abordagens diferentes, ou seja, considerando diferentes substâncias na sua caracterização. 
Figura 15 - Contribuição dos processos no sistema de superestrutura para depleção fóssil (unidade funcional de $1,0 \mathrm{~m}^{2}$ de área construída)

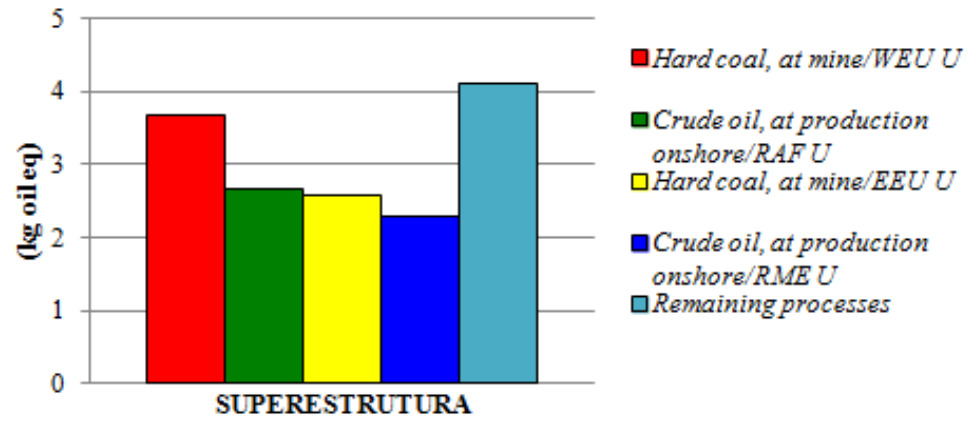

Fonte: Medeiros (2016).

Figura 16 - Contribuição dos processos no sistema de vedação para depleção fóssil (unidade funcional de $1,0 \mathrm{~m}^{2}$ de área construída)

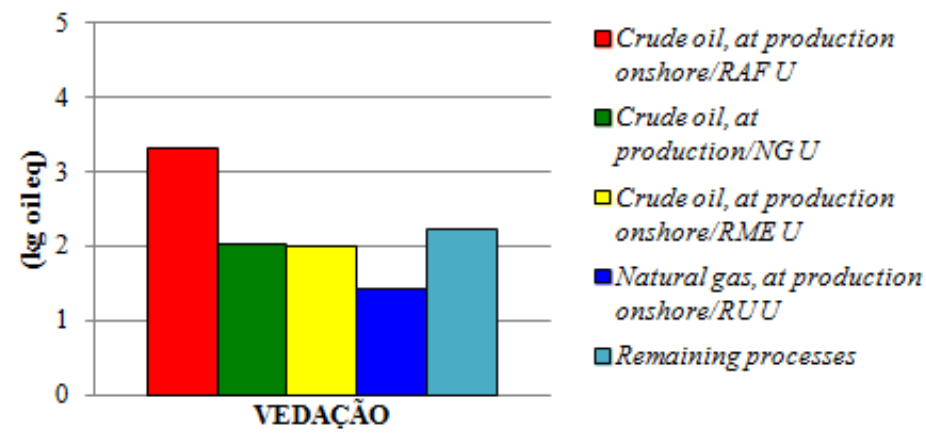

Fonte: Medeiros (2016).

Figura 17 - Análise de sensibilidade entre os métodos ReCiPe e CML 2 Baseline (unidade funcional de $1,0 \mathrm{~m}^{2}$ de área construída)

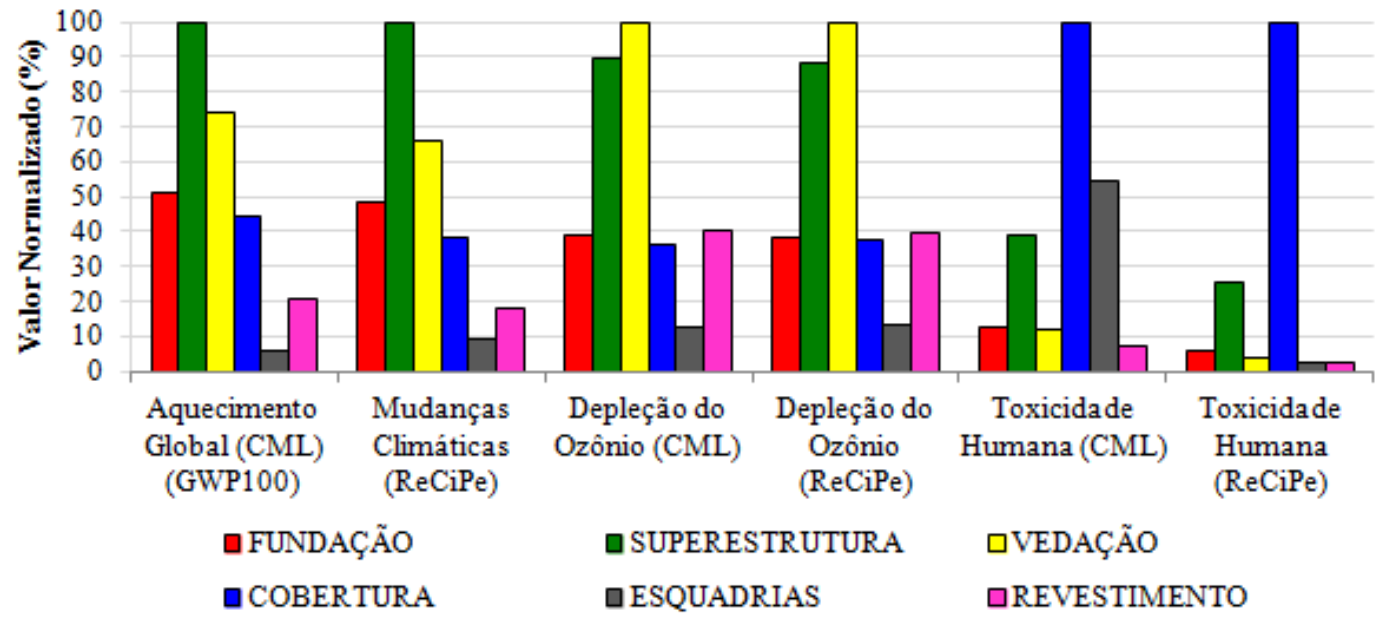

Fonte: Medeiros (2016). 
Tabela 2 - Análise de sensibilidade a diferentes metodologias de AICV (ReCiPe e CML 2 Baseline) (unidade funcional de $1,0 \mathrm{~m}^{2}$ de área construída)

\begin{tabular}{|c|c|c|c|c|c|c|}
\hline Componentes & $\begin{array}{l}\text { Aquecimento } \\
\text { Global (CML) } \\
\text { (GWP100) } \\
\left(\mathrm{kg} \mathrm{CO}_{2} \text { eq) }\right.\end{array}$ & $\begin{array}{l}\text { Mudanças } \\
\text { Climáticas } \\
(\mathrm{ReCiPe}) \\
\left(\mathrm{kg} \mathrm{CO}_{2} \text { eq) }\right.\end{array}$ & $\begin{array}{c}\text { Depleção do } \\
\text { Ozônio (CML) } \\
\text { (kg CFC-11 eq) }\end{array}$ & $\begin{array}{c}\text { Depleção do } \\
\text { Ozônio } \\
\text { (ReCiPe) } \\
(\mathrm{kg} \mathrm{CFC}-11 \text { eq) }\end{array}$ & $\begin{array}{c}\text { Toxicidade } \\
\text { Humana } \\
\text { (CML) } \\
\text { (kg 1,4-DB eq) }\end{array}$ & $\begin{array}{c}\text { Toxicidade } \\
\text { Humana } \\
\text { (ReCiPe) } \\
\text { (kg 1,4-DB eq) }\end{array}$ \\
\hline FUNDAÇÃO & 55,96 & 61,13 & $2,58 \mathrm{E}-06$ & $2,62 \mathrm{E}-06$ & 8,75 & 3,86 \\
\hline ESTRUTURA & 109,31 & 125,67 & $5,97 \mathrm{E}-06$ & $6,09 \mathrm{E}-06$ & 27,58 & 16,59 \\
\hline VEDAÇÃO & 81,15 & 82,55 & $6,66 \mathrm{E}-06$ & $6,88 \mathrm{E}-06$ & 8,66 & 2,61 \\
\hline COBERTURA & 48,59 & 48,41 & $2,43 \mathrm{E}-06$ & $2,58 \mathrm{E}-06$ & 70,95 & 65,23 \\
\hline ESQUADRIAS & 6,73 & 11,27 & $8,26 \mathrm{E}-07$ & $9,00 \mathrm{E}-07$ & 38,45 & 1,71 \\
\hline REVES TIMENTO & 22,65 & 22,60 & $2,67 \mathrm{E}-06$ & $2,74 \mathrm{E}-06$ & 5,08 & 1,56 \\
\hline
\end{tabular}

Fonte: Medeiros (2016).

\section{Análise de incerteza}

A análise de incerteza dos resultados foi realizada a partir da técnica de Monte Carlo, integrada ao software SimaPro 8.0, baseada nos valores de desvio padrão relativo calculado para cada material inventariado. A Figura 18 apresenta, para cada categoria, a margem de incerteza absoluta, e as linhas verticais indicam o intervalo de confiança de $95 \%$.

Analisando-se os resultados associados às incertezas absolutas envolvidas nos sistemas e processos, pode-se afirmar que é alto o grau de incerteza para este estudo. Verifica-se que a maior incerteza está associada ao sistema de cobertura e vedação, visto que tiveram seus processos modelados simplificadamente.

Para categorias mais consolidadas, como mudanças climáticas, o grau de incerteza é relativamente menor, devido à adoção do mesmo indicador do International Panel on Climate Change (IPCC) no cálculo do potencial de aquecimento global (GWP), diferentemente do que se observa em outras categorias, nas quais a modelagem para quantificar os impactos decorrentes das emissões ainda precisa de maior aprofundamento e o grau de incerteza é maior (HAUSCHILD et al., 2012).

\section{Interpretação do resultado da ACV Identificação das questões significativas}

A análise de contribuição em cada sistema identificou os processos que estão diretamente ligados aos potenciais impactos ambientais de cada sistema. No sistema de superestrutura, os impactos estão associados, principalmente, aos processos de fabricação de clínquer na categoria de mudanças climáticas; ao processo de produção de fôrmas de madeira, que, durante a fase de serragem e produção das toras, apresentam alto potencial de impacto na categoria de formação de material particulado; à fabricação do concreto, na categoria de depleção da água; e ao consumo de carvão mineral nos processos de fabricação de clínquer e de ferro gusa, na categoria de depleção fóssil.

No sistema de cobertura, a análise de contribuição demonstrou que a produção do zinco para telhas metálicas foi o processo com maior potencial de impacto, devido às grandes quantidades de emissões de substâncias tóxicas para o ar e devido à extração de recursos minerais, o que gera impactos nas categorias de toxicidade humana e depleção de metais. Esses impactos ligados à produção de aço podem ser reduzidos se for considerada a reciclagem na produção do zinco, reduzindo a necessidade de novas extrações.

A análise de contribuição do sistema de vedação indicou que a extração de petróleo foi o processo com maior potencial de impacto para a categoria de depleção do ozônio, isso porque nesse processo são utilizados gases halons que apresentam alto potencial de destruição da camada de ozônio. Considerando que esses gases são proibidos no Brasil, esse resultado não pode ser considerado verdadeiro para a realidade brasileira, sendo indicada a modelagem desse processo considerando dados regionais.

Os sistemas de esquadrias, revestimentos e fundação apresentaram uma pequena influência nos impactos totais do edifício, em todas as categorias.

\section{Avaliação do estudo}

Os resultados da análise de sensibilidade quanto à escolha do método de AICV demonstraram que não houve variação das contribuições dos sistemas nas categorias analisadas. A maior variação encontrada foi na categoria toxicidade humana, em que se verificou aumento nas emissões do sistema de esquadrias. 
Figura 18 - Análise de incerteza em que o coeficiente de variação foi estimado utilizando a combinação Matriz Pedigree com a simulação Monte Carlo (1.000 interações; 95\% de confiança)

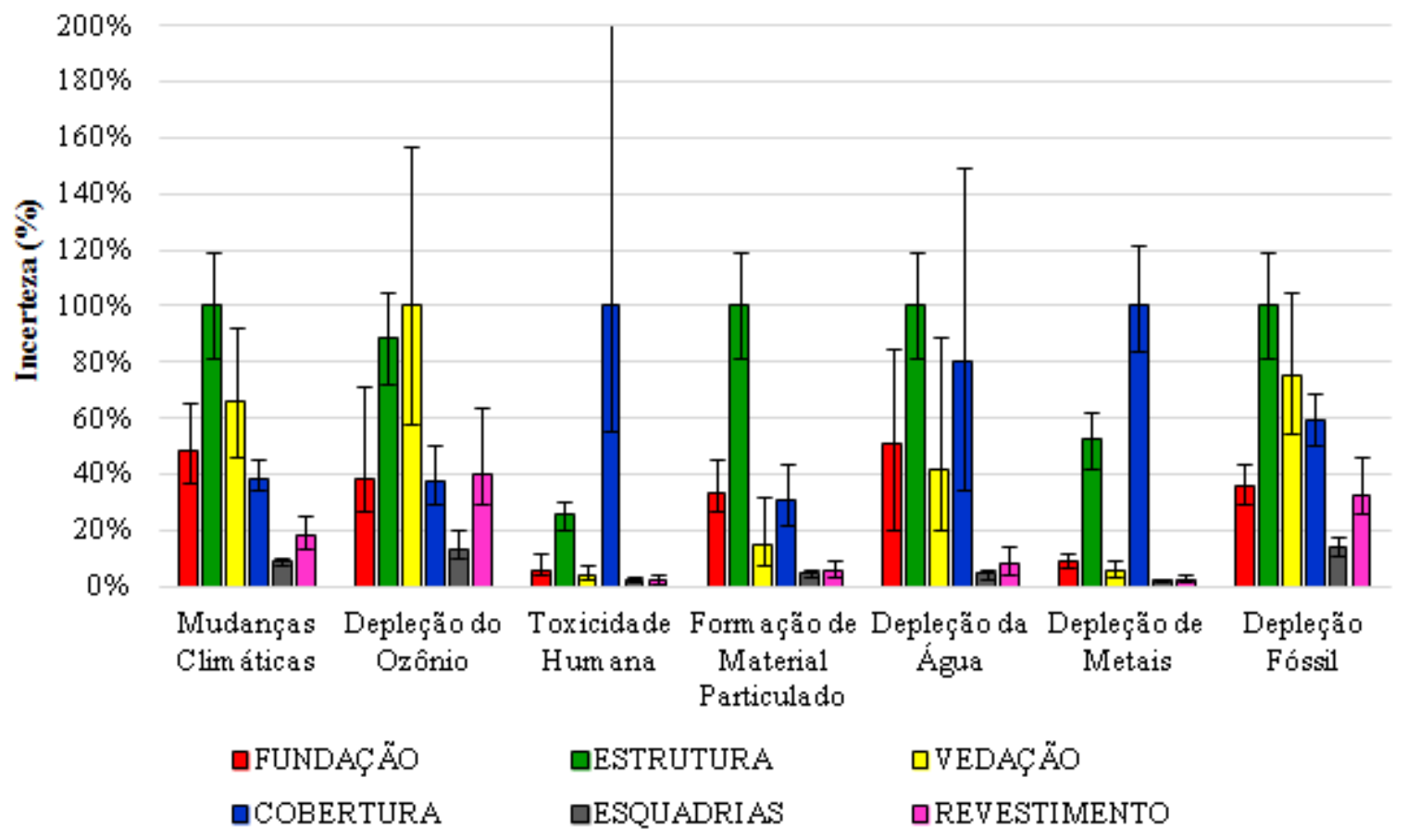

Fonte: Medeiros (2016).

Quanto à consistência dos dados, a análise de incerteza demonstrou alto grau de incerteza para os sistemas de cobertura e vedação, para os quais foram assumidas modelagens simplificadas. A simplificação foi adotada devido à ausência de inventários, o que indica a necessidade da construção dessa documentação para aplicação em estudos de ACV.

É importante destacar que todos os dados de inventário do estudo foram extraídos da base de dados Ecoinvent, a qual é composta por dados majoritariamente coletados para a realidade europeia. Isso também confere grau de incerteza quanto à sua aplicação a um cenário brasileiro.

\section{Conclusões e limitações}

Apesar dos resultados indicarem o sistema de superestrutura como o que apresenta maior potencial de impacto ambiental na maioria das categorias, as incertezas envolvidas no estudo demonstram que essa afirmativa só pode ser confirmada para a categoria de formação de material particulado, pois para as demais categorias as incertezas podem alterar o ranqueamento dos sistemas nos resultados finais.

Quanto à análise de contribuição dos processos, conclui-se que os processos de fabricação do clínquer e produção do aço são altamente contributivos nas categorias de impacto. Para o primeiro, devem ser investigadas alternativas menos impactantes em substituição ao clínquer ou materiais que usam menos clínquer e, para o segundo, deve-se considerar a reciclagem do aço.

A principal limitação do estudo está na inexistência de metodologias de AICV e base de dados de inventário desenvolvidos para a realidade brasileira, o que confere ao estudo incertezas quanto à sua aplicação nacional.

\section{Considerações finais}

Esta pesquisa permitiu concluir que a ACV é uma metodologia adequada para avaliação ambiental quantitativa de materiais e sistemas construtivos, porém sua complexidade de aplicação, ausência de bases de dados regionalizadas e o dissenso quanto à metodologia mais adequada para a realidade brasileira são fatores que dificultam o uso e a popularização dessa metodologia.

Os principais gargalos quanto à ausência de informações foram verificados na fase de modelagem no software Simapro 8.0, pois os materiais referentes a argamassas de assentamento, chapisco e emboço, telha termoacústica, porcelanato, granilite e esquadrias de alumínio não foram localizados no banco de dados Ecoinvent, e, por esse motivo, foram modelados 
simplificadamente a partir dos materiais primários que os compõem.

Aponta-se, para trabalhos futuros, a necessidade de elaboração de um banco de dados brasileiro, pois, além da inexistência desses materiais citados, os materiais existentes foram modelados considerando os processos europeus de fabricação e, portanto, podem apresentar algumas divergências em relação aos brasileiros.

Outra dificuldade foi quanto à escolha do método de AICV, uma vez que também não existe um consenso sobre o mais adequado para estudos desenvolvidos para a realidade brasileira.

Expostos esses motivos, acredita-se que este trabalho contribuiu para demonstrar que, apesar das limitações, é possível desenvolver estudos de ACV aplicados a sistemas construtivos de edifícios e, principalmente, para a divulgação dessa metodologia no contexto geográfico de Mato Grosso no âmbito da construção civil.

Mesmo que as incertezas envolvidas no estudo tenham sido altas, esta pesquisa possibilitou depreender resultados importantes para que a indústria da construção civil possa melhorar seus processos e produtos.

\section{Referências}

AKTAS C. B.; BILEC, M. M. Impact of Lifetime on US Residential Building LCA Results.

International Journal of Life Cycle Assessment, v. 17, p. 337-349, 2012.

ASIF, M.; MUNEER, T.; KELLEY, R. Life Cycle Assessment: a case study of a dwelling home in Scotland. Building and Environment, v. 42, p. 1391-1394, 2007.

ASSOCIAÇÃO BRASILEIRA DE NORMAS TÉCNICAS. NBR 15575-1: edificações habitacionais: desempenho: parte 1: requisitos gerais. Rio de janeiro, 2013.

\section{ASSOCIAÇÃO BRASILEIRA DE NORMAS}

TÉCNICAS. NBR ISO 14040: avaliação do ciclo de vida: princípios e estrutura. Rio de Janeiro, 2009a.

\section{ASSOCIAÇÃO BRASILEIRA DE NORMAS} TÉCNICAS. NBR ISO 14044: gestão ambiental: avaliação do ciclo de vida: requisitos e orientações. Rio de Janeiro, 2009b.

BENEDET JUNIOR, G. Avaliação de Incertezas em Inventários do Ciclo de Vida. Florianópolis, 2007. Dissertação (Mestrado em Engenahria Civil) - Escola de Engenharia, Universidade Federal de Santa Catarina, Florianópolis, 2007.
BILEC, M. M. et al. Life-Cycle Assessment Modeling of Construction Processes for Buildings. Journal of Infrastructure Systems, v. 17, p. 199205, 2010.

BLENGINI, G. A.; DI CARLO, T. Energy-Saving Policies and Low-Energy Residential Buildings: an LCA case study to support decision makers in Piedmont (Italy). Internatonal Journal Life Cycle Assessment, v. 15, p. 652-665, 2010.

\section{BRITISH STANDARDS. EN 15978:}

sustainability of construction works: assessment of environmental performance of buildings: calculation method. European Committee for Standardization. 2011.

BUENO, C. et al. Sensitivity Analysis of the Use of Life Cycle Impact Assessment Methods: a case study on building materials. Journal of Cleaner Production, v. 112, p. 2208-2220, 2016.

CABEZA, L. F. et al. Life Cycle Assessment (LCA) and Lifecycle Energy Analysis (LCEA) of Buildings and the Building Sector: a review.

Renewable and Sustainable Energy Reviews, v. 29, p. 394-416, 2014.

CAIXA ECONÔMICA FEDERAL. Sistema Nacional de Pesquisa de Custos e Índices da Construção Civil. Tabela de Custos de Composições Analítica. 2016. Disponível em: <http://www.caixa.gov.br/poder-publico/apoiopoder-publico/sinapi/Paginas/ default.aspx $>$. Acesso em: 15 fev. 2016.

CAMPOS, F. H. A. Análise do Ciclo de Vida na Construção Civil: um estudo comparativo entre vedações estruturais em painéis pré-moldados e alvenaria em blocos de concreto. Belo Horizonte, 2012. Dissertação (Mestrado em Engenharia Civil) - Escola de Engenharia, Universidade Federal de Minas Gerais, Belo Horizonte, 2012.

CARLISLE, S.; FRIEDLANDER, E. The Influence of Durability and Recycling on Life Cycle Impacts of Window Frame Assemblies. International Journal of Life Cycle Assessment, v. 21, p. 1645-1657, 2016.

COSTA, R. V. G. Taxa de Geração de Resíduos da Construção Civil em Edificações na Cidade de João Pessoa. João Pessoa, 2012. Dissertação (Mestrado em Engenharia Civil) - Escola de Engenharia, Universidade Federal de Pernambuco, João Pessoa, 2012.

\section{EUROPEAN COMMISSION: JOINT} RESEARCH CENTER. International Reference Life Cycle Data System (ILCD) Handbook: general guide for life cycle assessment, detailed guidance. 2010. 
FAGUNDES, H. A. V. Diagnóstico da Produção de Madeira Serrada e Geração de Resíduo do Processamento de Madeira de Florestas Plantadas no Rio Grande do Sul. Porto Alegre, 2003. Dissertação (Mestrado em Engenharia Civil) - Escola de Engenharia, Universidade Federal do Rio Grande do Sul, Porto Alegre, 2003.

HANSEN, A. P. Análise do Efeito em Termos de Desempenho Ambiental da Substituição de Eteno de Origem Fóssil por Equivalente Renovável na Produção de Poliestireno. São Paulo, 2013. Dissertação (Mestrado em Engenharia Civil) - Escola de Engenharia, Universidade de São Paulo, São Paulo, 2013.

HAUSCHILD, M. Z. et al. Identifying Best Existing Practice for Characterization Modeling in Life Cycle impAct Assessment. The International Journal of Life Cycle Assessment, v. 18, n. 3, p. 683-697, 2012.

ISOESTE. Telha trapezoidal: características técnicas. Disponível em:

$<$ http://www.isoeste.com.br/portfolio_item/trapezo idal-pur-pir/>. Acesso em: 15 maio 2016.

LEWANDOWSKA, A. et al. Between Full LCA and Energy Certification Methodology: a comparison of six methodological variants of buildings environmental assessment.

International Journal of Life Cycle Assessment, v. 20, p. 9-22, 2015.

LIVESEY, K.; MACÉ, E. The Challenge of Measuring and Mitigating the Environmental Performance of Foundations and Substructures.

Foundations \& Substructures Briefing Paper, 2016.

LOPES, G. A. Avaliação do Ciclo de Vida de Dois Materiais de Isolamento Utilizados na Construção Civil: o poliestireno expandido e o aglomerado de cortiça expandida. Porto, 2011. Dissertação (Mestrado em Engenharia Civil) Escola de Engenharia, Universidade do Porto, Porto, 2011.

MACEDO, D. B. G. Metodologia de Avaliação do Ciclo de Vida de Sistemas Construtivos: aplicação em um sistema estruturado em aço. Belo Horizonte, 2011. Tese (Doutorado em Engenharia Civil) - Escola de Engenharia, Universidade Federal de Minas Gerais, Belo Horizonte, 2011.

MALMQVIST, T.; GLAUMANN, M. Selecting Problem-Related Environmental Indicators For Housing Management. Building Research and Information, v. 34, n. 4, p. 321-333, 2006.
MAURY, M. B.; BLUMENSCHEIN, R. N. Produção de Cimento: impactos à saúde e ao meio ambiente. Sustentabilidade em Debate, Brasília, v. 3, n. 1, p. 75-96, 2012.

MEDEIROS, L. M. Impactos Ambientais de Sistemas Construtivos: um exercício de análise de ciclo de vida. Cuiabá, 2016. Dissertação (Mestrado em Engenharia Civil) - Escola de Engenharia, Universidade Federal de Mato Grosso, Cuiabá, 2016.

MENDES, N. C.; BUENO, C.; OMETTO, A. R. Avaliação de Impacto do Ciclo de Vida: revisão dos principais métodos. Production, v. ahead, p. 1-16, 2013.

MINISTÉRIO DE MEIO AMBIENTE. Agenda Ambiental na Administração Pública. 2009.

Disponível em:

<http:/www.mma.gov.br/images/arquivo/80063/ cartilha\%20completa\%20A3P_.pdf $>$. Acesso em: 15 mar. 2015.

NASCIMENTO, M. A. Metodologia de Levantamento Energético Com Base na Análise do Ciclo de Vida na Construção Civil: estudo de caso no Centro Interdisciplinar de Energia e Ambiente da Universidade Federal da Bahia. Salvador, 2011. Tese (Doutorado em Engenharia Civil) - Escola de Engenharia, Universidade Federal de Bahia, Salvador, 2011.

OLIVEIRA, F. R. M. Integração de Indicadores de Desempenho Técnico-Funcional, Ambiental e Econômico de Sistemas Estruturais Verticais em Concreto. Campinas, 2013. Tese (Doutorado em Engenharia Civil) - Escola de Engenharia Civil, Universidade Estadual de Campinas, Campinas, 2013.

ORTIZ, O.; CASTELLS, F.; SONNEMANN, G. Sustainability in the Construction Industry: a review of recent developments based on LCA. Construction and Building Materials, v. 23, p. 28-39, 2009.

PACHECO-TORRES, R. P. et al. Analysis of $\mathrm{CO}_{2}$ Emissions in the Construction Phase of SingleFamily Detached Houses. Sustainable Cities and Society, v. 12, p. 63-68, 2014.

PASSUELLO, A. C. B. et al. Aplicação da Avaliação do Ciclo de Vida na Análise de Impactos Ambientais de Materiais de Construção Inovadores: estudo de caso da pegada de carbono de clínqueres alternativos. Ambiente Construído, Porto Alegre, v. 14, n. 4, p. 7-20, out./dez. 2014. 
PINI. Infra estrutura urbana. Equipamentos Públicos: Arena Pantanal. Edição 27 de maio de 2013. Disponível em:

$<$ http://infraestruturaurbana.pini.com.br/solucoestecnicas /27/arena-pantanal-estadio-de-r-5189milhoes-que-abrigara-288501-1.aspx>. Acesso em: jul. 2015.

PRÉ CONSULTANTS. SimaPro Database manual: methods library. Disponível em: $<$ https://www.presustainability.com/download/DatabaseManualMet hods.pdf $>$. Acesso em: 2 fev. 2016.

RODRIGUES, C. R. B. et al. Sistemas

Computacionais de Apoio a Ferramenta Análise de Ciclo de Vida do Produto (ACV). In: ENCONTRO NACIONAL DE ENGENHARIA DE PRODUÇÃO, 28., Rio de Janeiro, 2008. Anais... Rio de Janeiro, 2008.

ROSSI, E. Avaliação do Ciclo de Vida da Brita Para a Construção Civil: estudo de caso. São Carlos, 2013. Dissertação (Mestrado em Engenharia Civil) - Escola de Engenharia Civil, Universidade Federal de São Carlos, São Carlos, 2013.

SAADE, M. R. M. Influencia da Alocação de Impactos na Indústria Siderúrgica Sobre a Avaliação de Ciclo de Vida de Cimentos. Capinas, 2013. Dissertação (Mestrado em Engenharia Civil) - Escola de Engenharia, Universidade Estadual de Campinas, Campinas, 2013.

SANSÃO, J. H. Análise Ambiental de Alvenarias em Bloco. Belo Horizonte, 2011. Dissertação (Mestrado em Engenharia Civil) Escola de Engenharia Civil, Universidade Federal de Minas Gerais, Belo Horizonte, 2011.

SERVIÇO BRASILEIRO DE APOIO ÀS MICRO E PEQUENAS EMPRESAS. Centro Sebrae de Sustentabilidade. Nosso Trabalho. 2016. Disponível em: $<$ http://sustentabilidade.sebrae.com.br/Sustentabili dade/Nosso-trabalho/Nosso-trabalho>. Acesso em: 15 maio 2016.
SILVA, D. A. L. Avaliação do Ciclo de Vida da Produção do Painel de Madeira MDP no Brasil. São Carlos, 2012. Dissertação (Mestrado em Ciência e Engenharia de materiais) - Escola de Engenharia, Universidade de São Paulo, São Carlos, 2012.

SILVA, G. A.; YOKOTE, A. Y.; RIBEIRO, P. H. Desenvolvimento de Banco de Dados Brasileiro Para Avaliação de Ciclo de Vida. In: GLOBAL CONFERENCE - BUILDING A SUSTAINABLE WORLD, São Paulo, 2002. Proceedings... São Paulo, 2002.

SOARES, S. B.; SOUZA, D. M.; PEREIRA, S. W. A Avaliação do Ciclo de Vida no Contexto da Construção Civil. Construção e Meio Ambiente. Coleção Habitare. v. 7. Porto Alegre: ANTAC, 2006.

SOUZA, D. M. et al. Comparative Life Cycle Assessment of ceramic versus concrete roof tiles in the Brazilian context. Journal of Cleaner Production, v. 89, p. 165-173, 2015.

SUMNER, M.; GIANETTI, G.; BENINI, H. A Indústria do Cimento e Seu Papel na Redução das Emissões de $\mathrm{CO}_{2}$. Concretos \& Construções, v. 36, n. 51, ago./set. 2008.

TAIT. M. W.; CHEUNG, W. M. A Comparative Cradle-to-Gate Life Cycle Assessment of Three Concrete Mix Designs. International Journal of Life Cycle Assessment, v. 21, p. 847-860, 2016.

TAVARES, S. F. Metodologia de Análise do Ciclo de Vida Energético de Edificações Residenciais Brasileiras. Florianópolis, 2006. Tese (Doutorado em Engenharia Civil) - Escola de Engenharia, Universidade Federal de Santa Catarina, Florianópolis, 2006. 


\section{Larissa Mendes Medeiros}

Instituto Federal de Mato Grosso | Av. Tiradentes, 1300, Campus Várzea Grande, Petrópolis | Várzea Grande - MT - Brasil | CEP $78144-424$ | Tel.: (65) 3691-8000 | E-mail: larissa.medeiros@vgd.ifmt.edu.br

\section{Luciane Cleonice Durante}

Departamento de Arquitetura e Urbanismo, Pró-Reitoria de Ensino e Graduação | Universidade Federal de Mato Grosso |

Av. Fernando Corrêa da Costa, s/n, Coxipó da Ponte | Cuiabá - MT - Brasil | CEP 78060-900 | Tel.: (65) 3615-8975 |

E-mail: luciane.durante@hotmail.com

\section{Ivan J úlio Apolonio Callejas}

Faculdade de Arquitetura, Engenharia e Tecnlogia | Universidade Federal de Mato Grosso | Tel.: (65) 615-8774 |

E-mail: ivancallejas1973@gmail.com

\section{Revista Ambiente Construído}

Associação Nacional de Tecnologia do Ambiente Construído

Av. Osvaldo Aranha, 99 - 3o andar, Centro

Porto Alegre - RS - Brasil

$$
\text { CEP 90035-190 }
$$

Telefone: +55 (51) 3308-4084

Fax: +55 (51) 3308-4054

www. seer. ufrgs. br/ ambienteconstruido

E-mail: ambienteconstruido@ufrgs.br

(c) (i) This is an open-access article distributed under the terms of the Creative Commons Attribution License. 